\title{
Rotationally Sampled Wind Characteristics for Several Rotor Sizes Using Laser Anemometer Measurements
}

\author{
J. R. Connell
}

V. R. Morris

February 1989

Prepared for the U.S. Department of Energy under Contract DE-AC06-76RLO 1830

Pacific Northwest Laboratory

Operated for the U.S. Department of Energy by Battelle Memorial Institute 


\section{DISCLAIMER}

This report was prepared as an account of work sponsored by an agency of the United States Government. Neither the United States Government nor any agency thereof, nor Battelle Memorial Institute, nor any or their employees, makes any warranty, expressed or implied, or assumes any legal liability or responsibility for the accuracy, completeness, or usefulness of any information, apparatus, product, or process disclosed, or represents that its use would not infringe privately owned rights. Reference herein to any specific commercial product, process, or service by trade name, trademark, manufacturer, or otherwise does not necessarily constitute or imply its endorsement, recommendation, or favoring by the United States Government or any agency thereof, or Battelle Memorial Institute. The views and opinions of authors expressed herein do not necessarily state or reflect those of the United States Government or any agency thereof.

\section{PACIFIC NORTHWEST LABORATORY operated by \\ BATTELLE MEMORIAL INSTITUTE \\ for the \\ UNITED STATES DEPARTMENT OF ENERGY \\ under Contract DE-ACO6-76RLO 1830}

\begin{tabular}{|c|c|}
\hline \multicolumn{2}{|c|}{ Printed in the United States of America } \\
\hline \multicolumn{2}{|c|}{ Available from } \\
\hline \multicolumn{2}{|c|}{ National Technical Iniormation Service } \\
\hline \multicolumn{2}{|c|}{ United States Department of Commerce } \\
\hline \multicolumn{2}{|c|}{5285 Port Royal Road } \\
\hline \multicolumn{2}{|c|}{ Springfield, Virginia 22161} \\
\hline \multicolumn{2}{|c|}{ NTIS Price Codes } \\
\hline \multicolumn{2}{|c|}{ Microfiche $A 01$} \\
\hline \multicolumn{2}{|c|}{ Printed Copy } \\
\hline & Price \\
\hline Pages & Codes \\
\hline $001-025$ & A02 \\
\hline $026-050$ & $\mathrm{~A} 03$ \\
\hline $051-075$ & A04 \\
\hline $076-100$ & AOS \\
\hline $101-125$ & A06 \\
\hline $126-150$ & A07 \\
\hline $151-175$ & A0B \\
\hline $176-200$ & A09 \\
\hline $201-225$ & A10 \\
\hline $226-250$ & A11 \\
\hline $251-275$ & A12 \\
\hline $276-300$ & A13 \\
\hline
\end{tabular}


ROTATIONALLY SAMPLED WIND CHARACTERISTICS FOR SEVERAL ROTOR SIZES USING LASER ANEMOMETER MEASUREMENTS

J. R. Connell

V. R. Morris

February 1989

Prepared for the U.S. Department of Energy under Contract DE-AC06-76RLO 1830

Pacific Northwest Laboratory

Richland, Washington 993522 


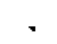




\section{SUMAARY}

The concept of measuring the wind velocity rotationally around crosswind circles using a circle-scanning Doppler laser anemometer is investigated to determine the technique's suitability as an effective, simple, economical, and nonintrusive method for estimating turbulence at a wind turbine rotor. Estimates of wind features obtained using the lidar technique are compared to actual wind measurements obtained using a vertical plane array of anemometers. and to other estimates generated using a single-tower technique. Although the lack of a common data set precludes a firm conclusion regarding the lidar method's accuracy, it appears that the rotationally scanning lidar has the potential of becoming an excellent tool for medsuring turbulent wind around the disk of rotation of a turbine blade. 
, 


\section{CONTENTS}

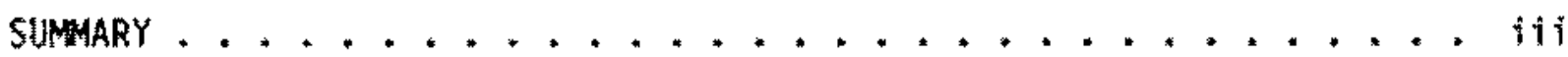

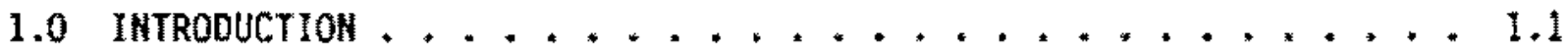

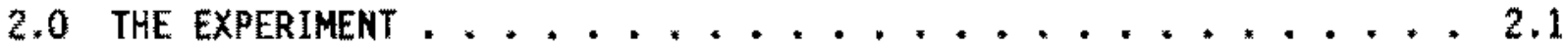

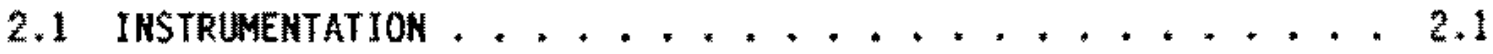

2.2 THE WIND CONDITIONS AND DATA SELECTION $\ldots \ldots \ldots$

3.0 ROTATIONALLY MEASURED WINO USING A DOPPLER LASER $\ldots \ldots \ldots$

3.1 LIOAR SYSTEM CONSTRAINTS ON THE MEASUREMENTS $\ldots \ldots \ldots$

3.2 ROTATIONAL TIME SERIES AND SPECTRA FROM LIDAR MEASUREMENTS $\ldots \ldots \ldots . \ldots \ldots . \ldots$

3.3 BAND OR PARTIAL VARIANCE DESCRIPTION OF LIDAR

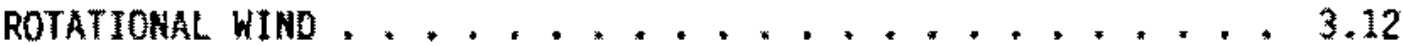

3.4 TURBULENCE LEVELS EXPERIENCED AT ROTORS, SCALED

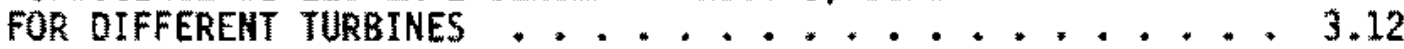

4.0 SIMULATION OF THE ROTATIONALLY SAMPLED WIND AROUND A CROSSWIND CIRCLE USING MEASUREMENTS WITH ANEMOMETERS

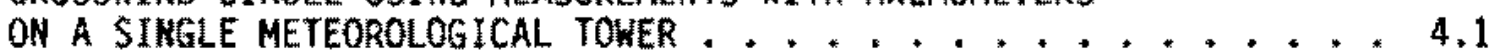

5.0 FURTHER DISCUSSION OF ACCURACY AND APPLICABILITY OF LIDAR AND SINGLE-TOWER METHODS OF ESTIMATING THE ROTATIONALLY MEASURED WIND SPEED $\ldots \ldots \ldots \ldots \ldots \ldots \ldots \ldots \ldots \ldots \ldots \ldots$

5.1 ACCURACY of THE STRS-2 METHOD ............... 5.1

5.2 ACCURACY OF THE ROTATIONALLY SCANHING LIOAR . . . . 5.2

6.0 CONCLUDING REMARKS AND RECONMENDATIONS .......... 6.1

6.1 DEPENDENCE OF ROTATIONALLY SAMPLED WIND CHARACTERISTICS ON ROTOR SIZE $\ldots \ldots \ldots \ldots \ldots . \ldots \ldots . \ldots . \ldots . \ldots$

6.2 RECOMMENDATION FOR CONTINUED RESEARCH ......... 6.2

6.3 THE RELATIVE MERITS OF STRS-2 AND CIRCLE-SCANNING LIDAR ...................... 6,4

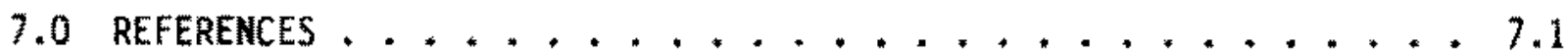




\section{FIGURES}

2.1 The Instrument Setup Used to Obtain Rotationally Measured Winds with the Lidar ...............2.2

2.2 A More Detalled Description of the Atmospheric Conditions for Each Subcase of Case 1 .......... 2.6

2.3 A More Detailed Description of the Atmospheric Conditions for Each Subcase of Case $2 \ldots \ldots . \ldots . \ldots$

2.4 A More Detailed Description of the Atnospheric Conditions for Each Subcase of Case 3 ........... 2.10

3.1 The MOD-OA Subcase Showing the Geometry of a Scanned

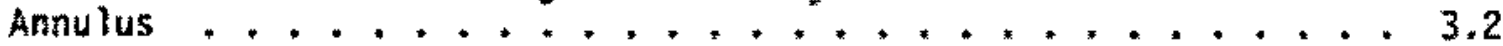

3.2 Graphs of Fluctuations of Wind Speed for 10 Rotations, Measured with the Scanning Lidar for Case 1 Wind

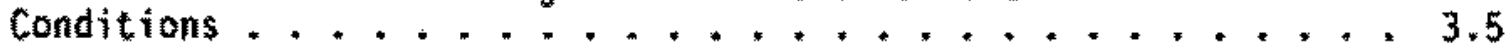

3.3 Spectral Density Curves for 13.6-min Corresponding to the case 1 Tine Series Shown in Figure $3.2 \ldots \ldots . \ldots$

3.4 Spectral Density Curves for 13.6-min Corresponding to the Case 2 Time Series Shown in Figure $3.2 \ldots \ldots . . \ldots$

3.5 Spectral Density Curves for 13.6-min Corresponding to the Case 3 Time Series Shown in Figure 3.2 ........ 3.10

3.6 Plots of Sets of Five Variances, One Associated with Each Spectral Harmonic Band ............. 3.12

3.7 A Plot of the Sum of the Variance for All Five Harmonic Bands as a Function of the Nondimensional Rotor Radius, $\mathrm{R} / \mathrm{Hi}$, Where $\mathrm{H}_{\mathfrak{i}}$ is the Hub Height for Each of the Three Wind Cases ..... 3.14

4.1 A Tíne Series of STRS-2 Simulated Rotationally Sampled Wind Speed for Subcase $c$ of Wind Case 2, Shown as a Solid Line in the Lower Graph .................... 4.2

4.2 The Turbulence Spectra of the STRS-2-Modeled Winds, Case $1 \ldots . .4$

4.3 The Turbulence Spectra of the STRS-2-Modeled Winds, Case $2 \ldots 4.5$

4.4 The Nondimensional Band Variances, $\sigma j^{2} / \Sigma \sigma j 2$, Associated with Each Multiple of the Sampling Rotation Rate, Plotted as a Function of the Nondimensional Center Frequency of Each Band, $n_{i} / n_{0} \ldots \ldots \ldots, \ldots . \ldots . \ldots$. 
4.5 A Plot of Correction Factors for the STRS-2 at the BAD Site for the Wind Conditions 0ccurring During the Measurements, Using the Lidar Measurements as the Standard . . . . . . . . 4.9

5.1 A Sketch of the Lidar Beam Illustrating the Active Volume Beam Shape Determined by the Lidar Receiver Telescope

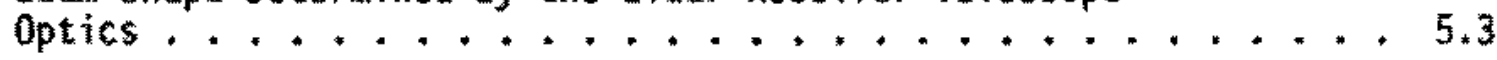

5.2 An Example of the Doppler Frequency Shift Spectrum

of Receiver Dutput Voltage for a Small Fraction

of the Time of one Rotor Blade Rotation $\ldots \ldots \ldots_{*}, \ldots+\ldots, 5.4$

5.3 The Geometry of the Laser Bean Axis and the Relevant Wind

Speed Components..........., ..., +........ 5.6

5.4 Hypothetical Plot of a Single Doppler Lidar Return Spectrum Showing Every Spectral Estimate, Spectral Frequency, $\mathrm{n}, \ldots+\ldots, \ldots+*_{*}+\ldots \ldots+\ldots$

6.1 A Plot of the Total Energy of Fluctuation in the HighFrequency part of the Rotationally Sampled Wind Spectrum Above the Frequency of Half the Rotation Frequency of 


\section{TABLES}

2.1 The Turbine Rotor and Lidar Parameters for Each Experiment

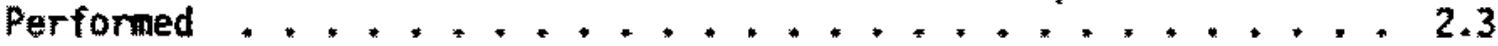

2.2 Some Mean Characteristics of the Atmosphere, and the Direction of the Bean of the Laser for Each Case and Subcase Analyzed .........................* 2.5 


\subsection{INTROOUCTION}

New information in the last 10 years has show that fluctuating forces on wind turbine blades, previously greatly underestimated, may correctly be calculated by taking into account the crosswind variation of velocity in the turbulent wind field (Connell 1980, 1982; Connell and George 1987). The validity of the rotationally sampled(a) wind concept was denonstrated in the referenced research using measurements of turbulent wind with a vertical plane array of anemometers set crosswind in front of a $125 \mathrm{ft}$ diameter wind turbine having a hub height of $100 \mathrm{ft}$.(b) A theoretical model of simple turbulent wind conditions observed in the rotating frame of reference verified the special features in the rotationally sampled wind observed with the anenometer array; the features were not artifacts of the digital and spatial sampling and the analys is technique.

A dynamically consistent comparison of the rotationally measured wind with the turbine blade bending moment fluctuations, observed at the same time, verified that the new wind concept provided the previously missing capability to explain observed turbine behavior. The cost and inflexibility of an adequate vertical plane array of anemometers, such as that used in the comparison, prohibited the extension of this method of research to large wind turbines, to complex terrain sites, or to each of a set of different locations.

The significance of the space and time variations of turbulence throughout the disk of a rotor, however, created a requirement to estimate the character, including the severity, of rotationally sampled wind for very large wind turbines of different rotor radi $i$, rotation rates, and hub heights. Versatile and lower-cost methods of rotational wind measurement were unavailable and had to be developed for this purpose. The quickest result cane from a Pacific Northwest Laboratory (PNL) model that simulated rotationally sampled wind by sampling and restructuring time series of turbulent wind measured by a set of

\footnotetext{
(a) The designation "rotationally sampled" was coined to identify the crosswind variation of wind velocity as it would be observed or measured in the rotating frame of reference of a wind turbine rotor blade.

(b) The 200-kh M00-0A wind turbine at Clayton, New Mexico.
} 
anenometers placed on single vertical line on a meteorological tower. The model was called STRS-2 for Single-Tower. Rotationally Sampled wind nodel, Version 2 (Conne 11 and George 1983b).

New measurements at wind turbines for STRS-2 analyses wold have required placing tall instrunented meteorological towers very close to the turbine rotors, a risky procedure. At about the same time at PNL, several other ideas for measuring the wind were concelved, including the concept of measuring the wind velocity rotationally around crosswind circles using a circle-scanning Doppler laser, (a) A pllot study corresponding to the conditions for a small wind turbine rotor configuration was implemented with the help of the National Oceanic and Atmospheric Administration/Wave Propagation Laboratory (NOAA/WPL) using a small lidar, (b) Those results encouraged a second, reportable study. Thus, the need for improved effectiveness, simplicity, econony, and nonintrusiveness of turbulence measurement at aind turbine rotor led to the laser anemometer experiment reported herein.

In the study reported here, concurrent independent measurements of wind velocity were made using a single meteorological tower at virtually the same location as the lidar. The conditions of rotation were for large wind turbines of a range of sizes from $200 \mathrm{~kW}$ to about $4 \mathrm{MW}$. This range of turbine sizes permits us to compare STRS-2 and the scanning lidar methods of estinating the same rotationally sampled wind velocity. The ideal comparison would have been to test the lidar method against the 7 -tower vertical plane array rotational sampling method used at the Clayton MOD-OA, which also spanned the

(a) Rotational scanning is the process of swinging the beam cyclically in such a fashion that the portion of the bean actively sensing, at a fixed distance from the bean source, follows a cicular path in nearly vertical plane. The Doppler laser evaluates the shift in the laser light frequency caused by the motion of the light scatterers carried by the wind. Ihis shift is proportional to the speed of movement of the scatterers along the direction of the bean axis relative to the nonmoying bean source.

(b) Lidar is the acronym for "light detection and ranging." It involves a coherent laser light source and instrumentation for transmitting an outgoing signal and receiving and processing an incoming signal in such a way that the existence of scatterers and the range to then is known. Additional processing is required to perform Doppler analys is of the velocity of the scatterers. The acronym does not include reference to the velocity analysis. 
erosswind disk and whose accuracy was known to be high. That comparison could not be made because of lidar unavailability when the array was operational.

STRS-2 has been tested against the complete vertical plane array at Clayton for 12 wind cases characteristic of that site and for the hub height, radius, and rotation rate of the MOD-OA wind turbine. STRS-2 remains our best method of concurrently comparing lidar measurenents with independent rotational estimates using wind measurements. The STRS-2 and lidar measurements for rotors of two larger turbines (the Mo0-2 and a generic MoD-5 with two rotor rates) compose the rest of the data. The connection of this comparison to the more suitable vertical plane array data (although for different wind and terrain conditions and year earlier) comes from inclusion of measurements with the two new techniques corresponding to the MOD-0A rotor configuration:

Neither the STRS-2 nor the lidar methods are considered at this time to be a suitable comparison standard for the other. We are, therefore, comparing two mostly untested nethods, and our recourse is to discuss the "apparent reasonableness" of the comparison of time series and spectra of wind velocity from the two methods.

The design of the experiment and the equipment used are described in Chapter 2. The andiysis of the wind data measured with the scanning Doppler laser (the lidar in a specific use) is described and discussed in Chapter 3. The STRS-2 results for the same cases are treated sinilarly in chapter 4 . A brief discusston of the accuracy and applicability of the two methods is made in chapter 5. This discussion includes some information on basic principles of lidar back-scatter in relation to real atmospheric conditions. Concluding remarks and recomendations are contained in chapter 6 . 


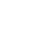




\subsection{THE EXPERIMENT}

\subsection{INSTRUMENTATION}

The instrument setup used to obtain rotationally measured winds with the lidar is shown in Figure 2.1. The turbine rotor and lidar parameters for each experiment performed are listed in Table 2.1. The beam of the laser was directed upward from the lidar trailer to a mirror mounted on an elevator carriage on the side of the $300-m$ meteorological tower at the NOAA Boulder Atmospheric Observatory (BAO) located in the near-downslope region on the eastern plains of Colorado. The mirror, attached to a slightly nonorthogonal axis of rotation, was set at an angle that directed the beam at a $10^{\circ}$ angle from the horizontal axis through the mirror. A motor drove the mirror in a rotary fashion about that axis causing the laser beam to trace out a right circular cone with a $10^{\circ}$ half-angle about a horizontal axis. The rotation of the beam was at the uniform rate corresponding to the wind turbine specified for each test.

The $10^{\circ}$ angle was chosen to give scanned circles of the radii desired, yet which were not too far from the tower where the winds were independently measured with fixed anemometers. The circles of interest could have been brought closer to the tower and to each other by using a larger cone angle, but the component of the wind measured was along the axis of the beam and at large cone angles would not have been a good measure of the wind in the direction of the axis of the cone. Indeed, if the axis of the cone were not along the direction of the wind for, say, several rotations or more, a false sinusoidal variation of the axial wind would be estimated. This false variation is small for a $10^{\circ}$ cone.

The laser was operated in continuous wave mode rather than pulse mode. The circle scanned by the active beam segment (i.e., the observed beam volume) was determined by focusing the receiver optics at an object distance from the apex of the cone that resulted in the correct circle radius. If a different turbine rotor radius was of interest, the focal distance was changed to observe the appropriate volume of the beam at a different distance from the apex of the cone. The depth of field of the receiver optics was a function of the focal distance. At the larger radii used, the active volume of the beam was 


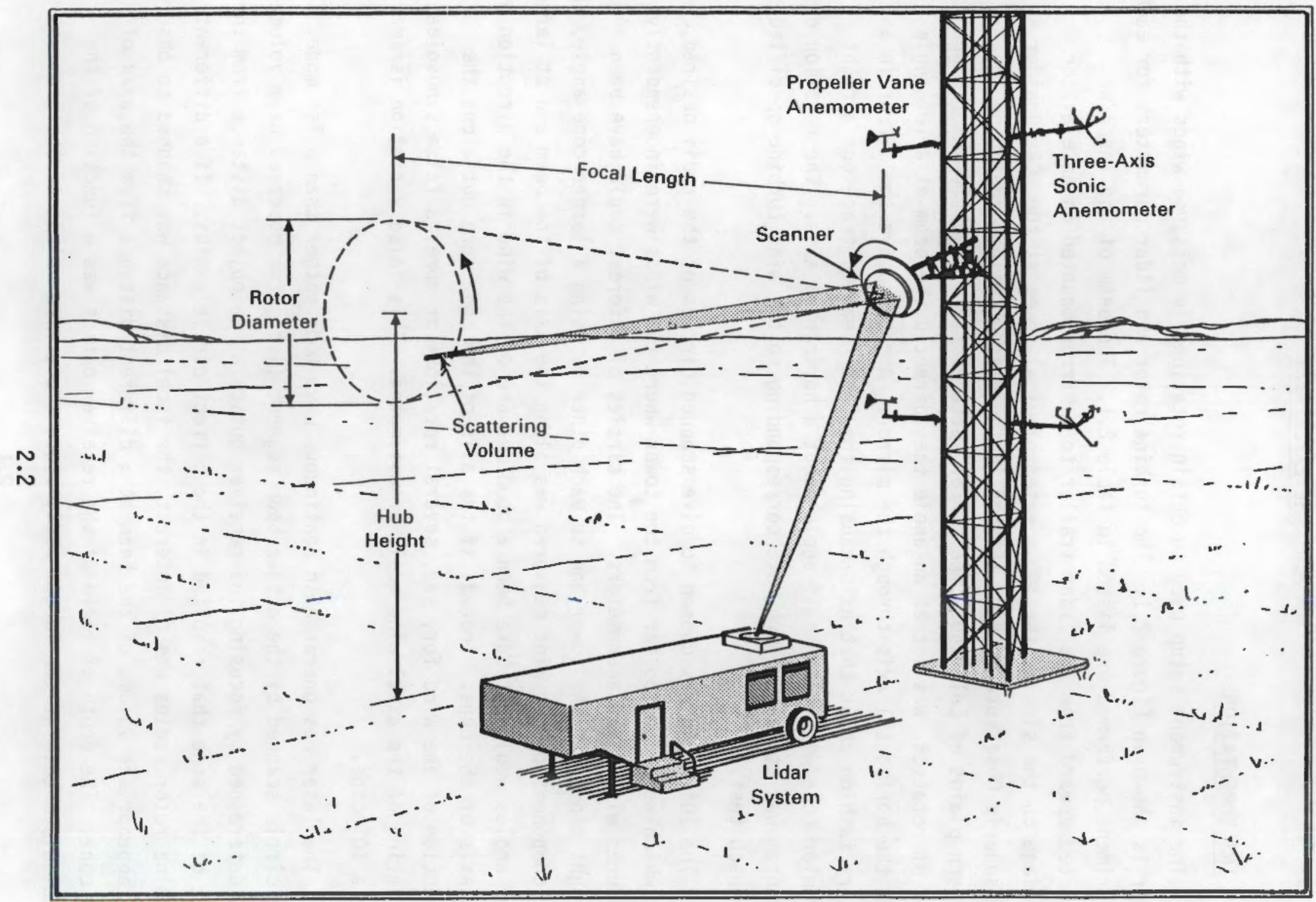

FIGURE 2.1. The Instrument Setup Used to Obtain Rotationally Measured Winds with the Lidar O O

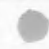
O ○ O 
TABLE 2.1. The Turbine Rotor and Lidar Parameters for Each Experiment Performed

\begin{tabular}{|c|c|c|c|c|c|c|c|c|}
\hline $\begin{array}{l}\text { Sub- } \\
\text { Case }\end{array}$ & $\begin{array}{l}\text { Wind } \\
\text { Turbine }\end{array}$ & $\begin{array}{c}3 \\
\text { Hub } \\
\text { Height, } \\
H \text { (m) } \\
\end{array}$ & $\begin{array}{c}4 \\
\text { Rotor } \\
\text { Radius, } \\
\text { R (m) } \\
\end{array}$ & $\begin{array}{c}5 \\
\text { Rotation } \\
\text { Rate, } \\
v(\text { rpm) }\end{array}$ & $\begin{array}{c}6 \\
\text { Sampling } \\
\text { Rate } \\
\text { (hz) } \\
\end{array}$ & $\begin{array}{c}7 \\
\text { Focal } \\
\text { Length } \\
\text { (m) } \\
\end{array}$ & $\begin{array}{c}8 \\
\text { Range } \\
\text { Resolution, } \\
\Delta R(\mathrm{~m}) \\
\end{array}$ & $\underline{\Delta R / 2 R}$ \\
\hline a & MOD-5B & 76.2 & 61.0 & 10.0 & 5 & 427 & 70 & 0.57 \\
\hline b & MOD-5B & 76.2 & 61.0 & 15.0 & 5 & 427 & 70 & 0.57 \\
\hline c & MOD-2 & 61.0 & 45.7 & 17.5 & 5 & 322 & 37 & 0.40 \\
\hline d & MOD-OA & 30.5 & 19.1 & 40.0 & 10 & 147 & 7 & 0.18 \\
\hline
\end{tabular}

a large fraction of the diameter of the circle being scanned. The most active portion of the beam was set at the radius of interest in each test. The mirror elevator was moved to place the height of the center of the circle scanned to each turbine rotor hub height.

At the beginning of each measurement period, the axis of the scanning cone was directed into the wind as observed by the wind vane on the tower at the height closest to each hub height selected. The wind was then rotationally measured using the lidar for 20 min for each of the four combinations of rotor diameter, hub height, and rotation rate. To repeat, only the one component, the nearly axial wind speed, was measured by the lidar method.

Independent measurements of the three orthogonal components of the wind and the air temperature from sensors mounted at eight heights on the tower were recorded concurrent with the lidar measurements. The horizontal winds were measured with both sonic anemometers and propeller-vane anemometers. The temperatures were measured with quartz thermometers. The anemometers used in each experiment were those on the current windward side of the tower. The laser beam and mirror were always placed so that the beam was reflected upwind from the windward side of the tower.

A number of individual experiment cases were included in the original data taken by NOAA/WPL. Papers analyzing some of the data and describing the lidar system in detail, including the parameters of the measuring beams in relation to atmospheric parameters and accuracy statements and measurement techniques, have been published by NOAA/WPL (Hardesty, Korrell and Hall 1981; Hardesty 
et al. 1981; Hardesty and Weber 1984). Additional discussion of accuracy is given in Chapter 5 of the present report. This report is based upon a PNL analysis of the original wind data provided by NOAA/WPL. The cases analyzed represent the more stationary and accurate wind data sets from both the meteorological tower and the rotationally scanning lidar.

\subsection{THE WIND CONDITIONS AND DATA SELECTION}

Data for three wind conditions, identified as Cases 1, 2, and 3, were selected for analysis. In each case, four 20-min time series were obtained, corresponding to each of the four wind turbine rotor geometry and rotation specifications, identified as a, b, $c$, and $d$ (see Table 2.1). The wind speeds were rather light for wind turbine operation, 3.2 to $8.7 \mathrm{~m} / \mathrm{s}$, and variable. In all of the cases, the mean wind speed varied significantly from one subcase to the next. During Case 2, the horizontally local static stability of the atmosphere changed from nearly neutral to stable and finally to very stable. The three experiments were carried out during a 3-week period in June and July of 1983 .

The mean parameters of the atmosphere and the direction of the beam of the laser for each case and subcase analyzed (1a to $d, 2 a$ to $d$, and $3 a$ to d) are recorded in Table 2.2. The table gives the date, time, axial wind speed at hub height, vertical shear of the axial wind speed across the disk of rotation, static stability across the disk, wind direction at hub height, and the direction of the laser beam. More detailed descriptions of the atmospheric conditions for each subcase are provided in Figures 2.2, 2.3, and 2.4. The plots of vertical profiles of bulk wind speed shear and bulk temperature gradient were derived from measurements made with the NOAA/WPL BAO tower instrumentation.

The wind speed profiles are of the component of the wind parallel to the mean direction of the laser beam. The bulk vertical shear of wind speed across the disk of rotation for each subcase, and the corresponding hub-height speed, are printed on each wind speed profile plot. The atmospheric bulk vertical gradient of temperature across the disk is printed on each graph of a temperature profile. A dotted line on the temperature plot indicates the temperature profile that would exist in a statically neutral, dry atmosphere. The profiles 
TABLE 2.2. Some Mean Characteristics of the Atmosphere, and the Direction of the Beam of the Laser

for Each Subcase Analyzed

\begin{tabular}{|c|c|c|c|c|c|c|c|}
\hline $\begin{array}{l}\text { Sub- } \\
\text { Case }\end{array}$ & $\begin{array}{c}\text { Date } \\
(1983)\end{array}$ & $\begin{array}{l}\text { Time } \\
\text { (MST) }\end{array}$ & $\begin{array}{c}\text { Radial } \\
\text { Wind Speed } \\
(\mathrm{m} / \mathrm{s})\end{array}$ & $\begin{array}{c}\text { Radial } \\
\text { Wind Shear } \\
\text { (m/s/m) }\end{array}$ & Stability & $\begin{array}{c}\text { Wind } \\
\text { Direction } \\
\text { (degrees) }\end{array}$ & $\begin{array}{c}\text { Beam } \\
\text { Direction } \\
\text { (degrees) } \\
\end{array}$ \\
\hline $\begin{array}{l}1 \mathrm{a} \\
1 \mathrm{~b} \\
1 \mathrm{c} \\
1 \mathrm{~d}\end{array}$ & $\begin{array}{l}6 / 23 \\
6 / 23 \\
6 / 23 \\
6 / 23\end{array}$ & $\begin{array}{l}1337 \\
1359 \\
1512 \\
1539\end{array}$ & $\begin{array}{l}8.2 \\
-- \\
5.1 \\
5.3\end{array}$ & $\begin{array}{c}0.010 \\
-- \\
0.031 \\
0.007\end{array}$ & $\begin{array}{c}\text { Neutral } \\
\text { Stable } \\
\text { Neutral }\end{array}$ & $\begin{array}{l}207 \\
-- \\
208 \\
225\end{array}$ & $\begin{array}{l}250 \\
250 \\
200 \\
200\end{array}$ \\
\hline $2 a$ & $7 / 01$ & 2156 & 3.5 & 0.025 & $\begin{array}{l}\text { Nearly } \\
\text { Neutral }\end{array}$ & 270 & 300 \\
\hline $\begin{array}{l}2 b \\
2 c \\
2 d\end{array}$ & $\begin{array}{l}7 / 01 \\
7 / 01 \\
7 / 02\end{array}$ & $\begin{array}{l}2217 \\
2328 \\
0010\end{array}$ & $\begin{array}{l}4.6 \\
4.6 \\
3.2\end{array}$ & $\begin{array}{r}0.025 \\
0.016 \\
-0.007\end{array}$ & $\begin{array}{l}\text { Stable } \\
\text { Stable } \\
\text { Very Stable }\end{array}$ & $\begin{array}{l}255 \\
245 \\
200\end{array}$ & $\begin{array}{l}300 \\
240 \\
210\end{array}$ \\
\hline $\begin{array}{l}3 a \\
3 b \\
3 c \\
3 d\end{array}$ & $\begin{array}{l}7 / 08 \\
7 / 08 \\
7 / 09 \\
7 / 09\end{array}$ & $\begin{array}{l}2314 \\
2340 \\
0030 \\
0055\end{array}$ & $\begin{array}{l}5.1 \\
5.6 \\
8.7 \\
5.9\end{array}$ & $\begin{array}{l}0.024 \\
0.035 \\
0.049 \\
0.052\end{array}$ & $\begin{array}{l}\text { Stable } \\
\text { Stable } \\
\text { Stable } \\
\text { Stable }\end{array}$ & $\begin{array}{l}308 \\
324 \\
328 \\
333\end{array}$ & $\begin{array}{l}320 \\
320 \\
320 \\
320\end{array}$ \\
\hline
\end{tabular}

are of values averaged over $13.6 \mathrm{~min}$. The horizontal bars through each mean data point represent the standard deviation of the fluctuations of the variable on either side of the mean value.

The four subcases of Case 1 were taken on June 23, 1983, from 1337 to 1559 MST, except that no data from the tower were collected from 1400 to 1420 . The atmosphere below $100 \mathrm{~m}$ was neutral, and the average wind speed at $50 \mathrm{~m}$ was from the south-southwest at $8.3 \mathrm{~m} / \mathrm{s}$.

Case 2 was undertaken on July 1, 1983, from 2156 to 0030 . The atmosphere was statically moderately stable, and the wind was from the west-southwest at $5.0 \mathrm{~m} / \mathrm{s}$. Case 3 was on July 8,1983 , from 2314 to 0115 . The atmosphere was locally moderately stable, and the wind was from the northwest at $5.7 \mathrm{~m} / \mathrm{s}$.

The mean profiles of the atmospheric parameters plus the rotor diameter, hub height, and blade rotation rate specify the experimental conditions for this study. The characteristics of these wind fields observed by a point simulating the motion following the tip of selected large wind turbine rotors are estimated in Chapter 3 for each subcase using rotationally scanning lidar measurements of wind. 


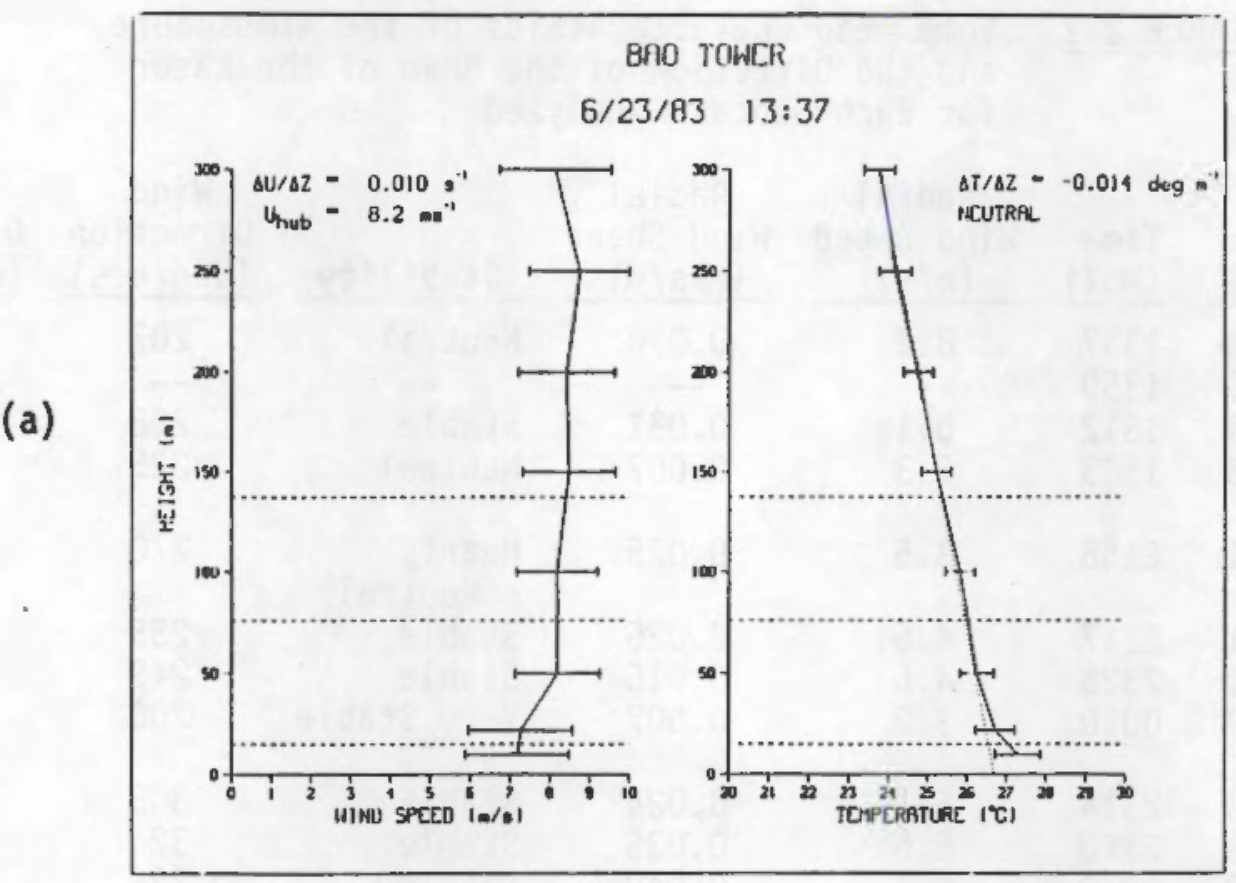

(b)

No Data Collected

FIGURE 2.2. A More Detailed Description of the Atmospheric Conditions for Each Subcase of Case 1. The plots of vertical profiles of bulk wind speed shear and bulk temperature gradient were derived from measurements made with the NOAA/WPL BAO tower instrumentation. (a) MOD-5B $10 \mathrm{rpm}$, (b) no data collected, (c) $M O D-2$, (d) $M O D-O A$. 

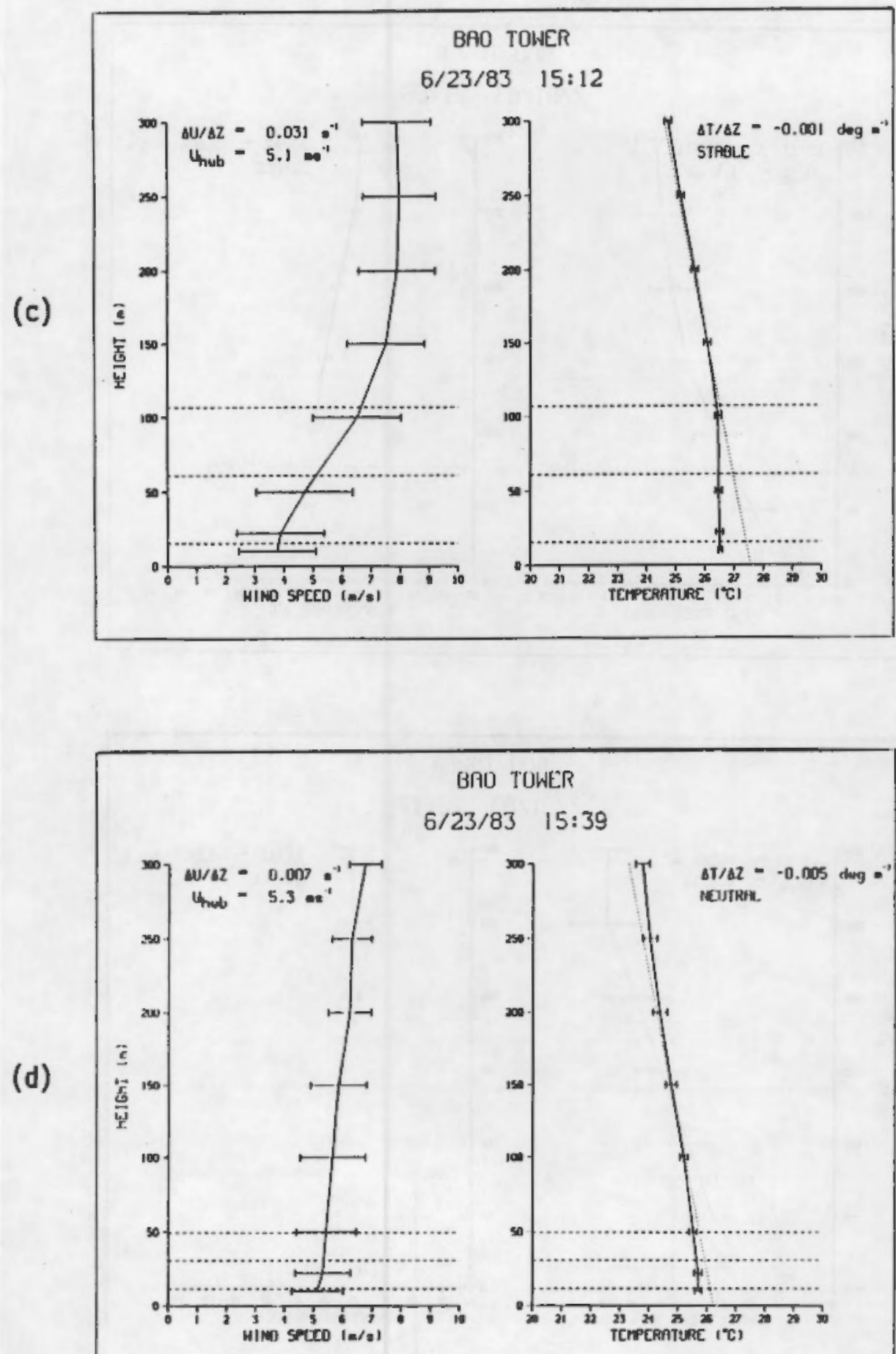

BRO TOWER

/5:39

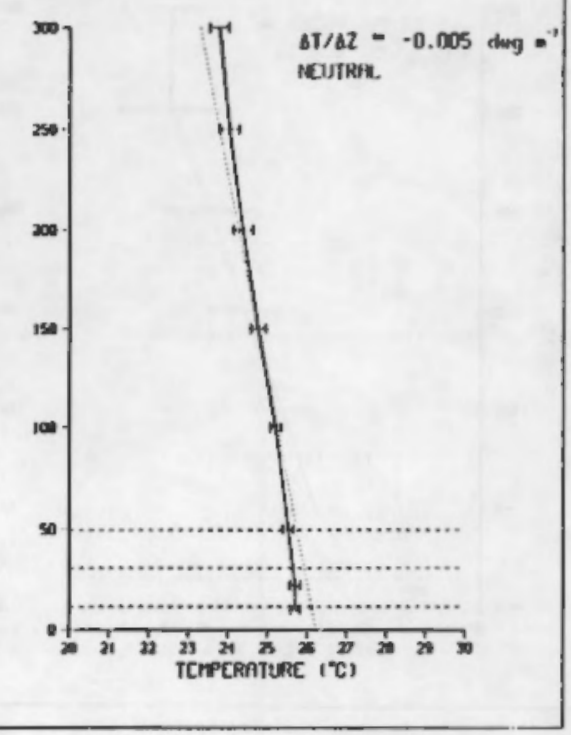

FIGURE 2.2. (contd) 
(a)

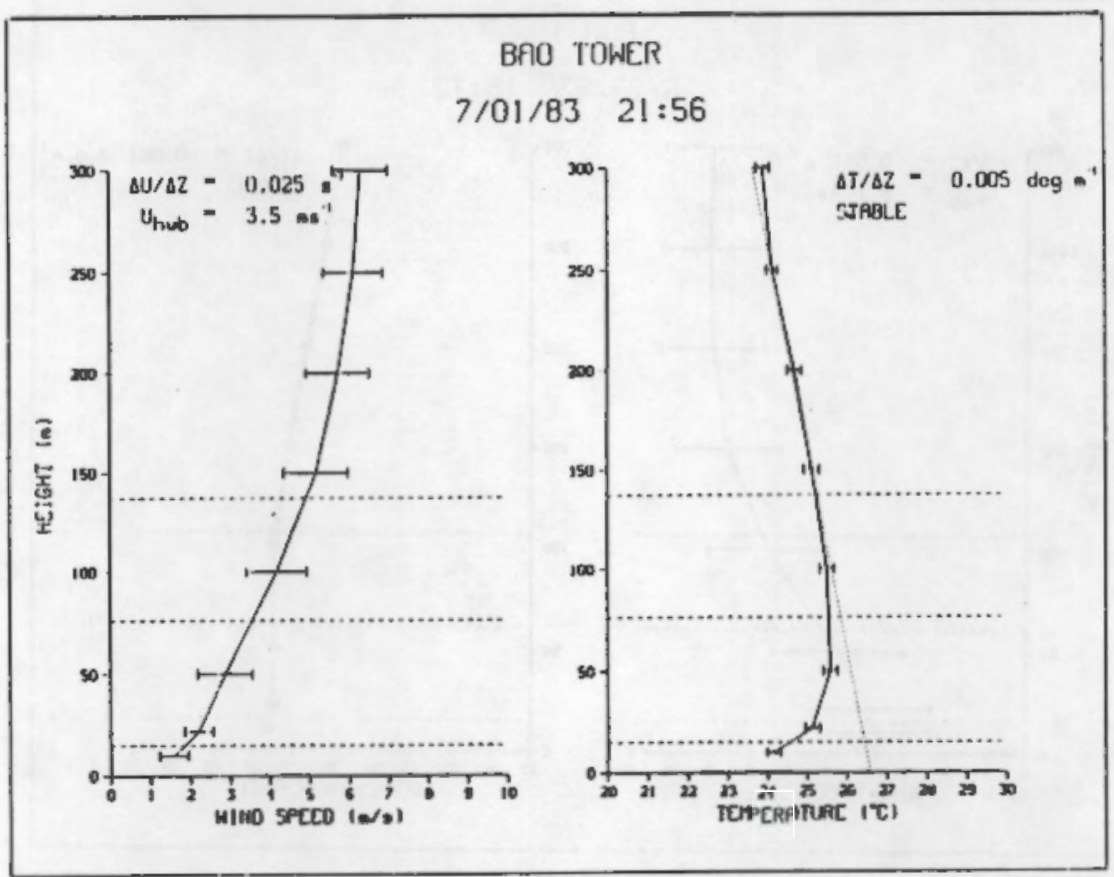

(b)

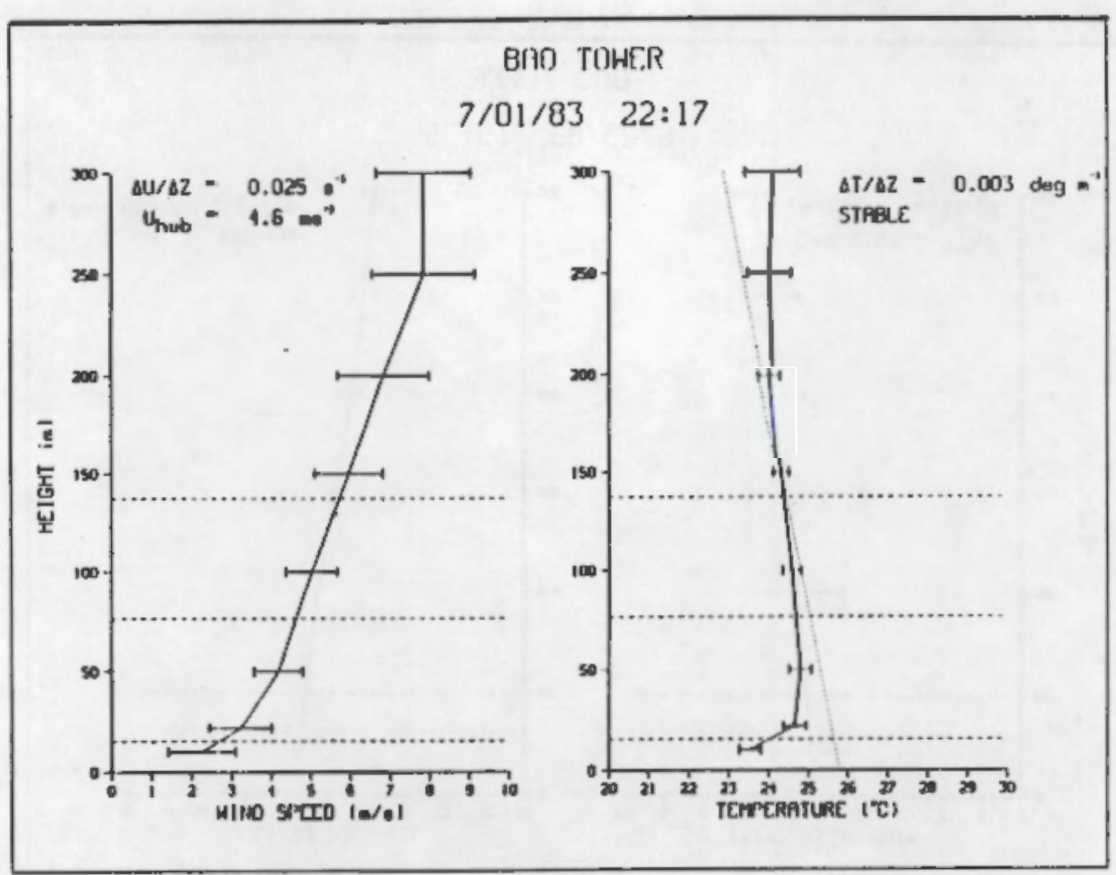

FIGURE 2.3. A More Detailed Description of the Atmospheric Conditions for Each Subcase of Case 2. The plots of vertical profiles of bulk wind speed shear and bulk temperature gradient were derived from measurements made with the NOAA/WPL BAO tower instrumentation. (a) MOD-5B $10 \mathrm{rpm}$, (b) MOD-5B $15 \mathrm{rpm}$, (c) $M O D-2$, (d) $M O D-O A$. 


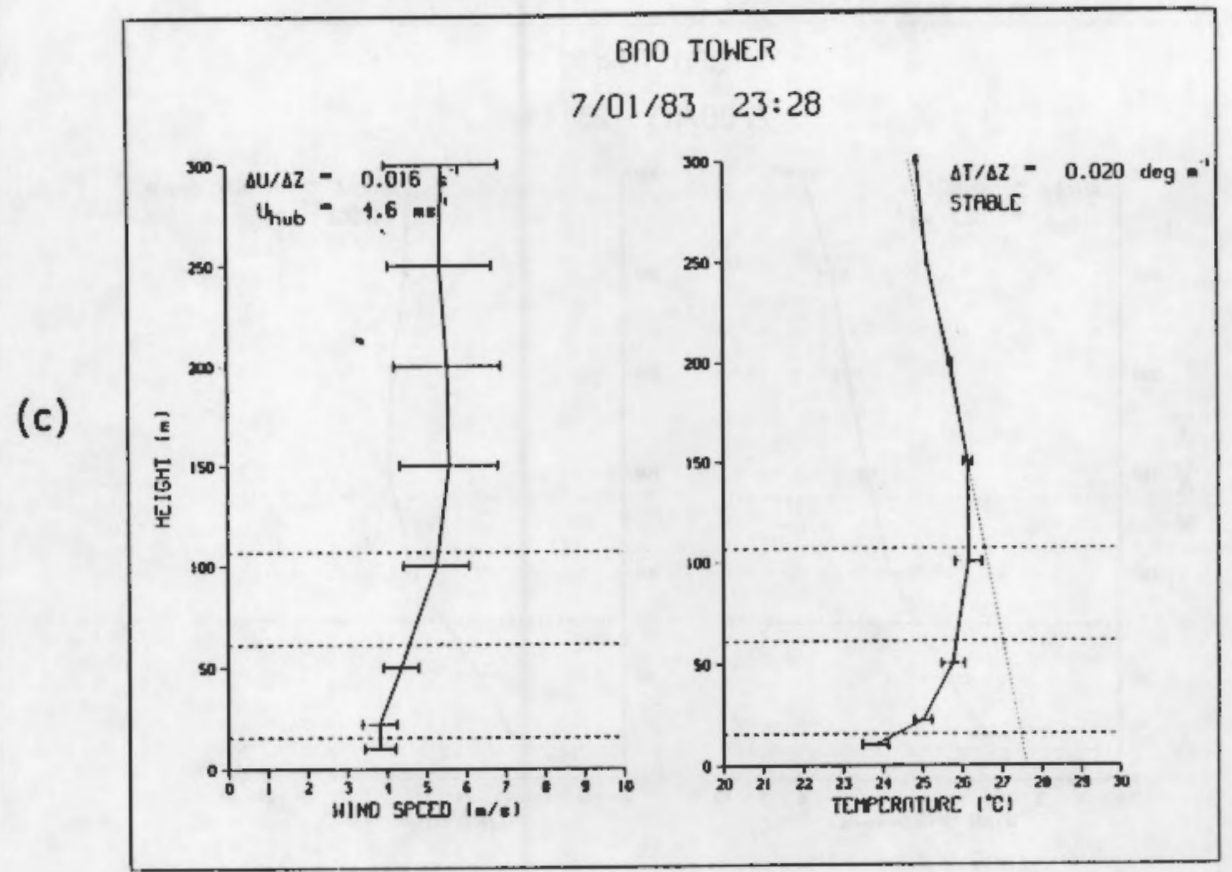

(d)

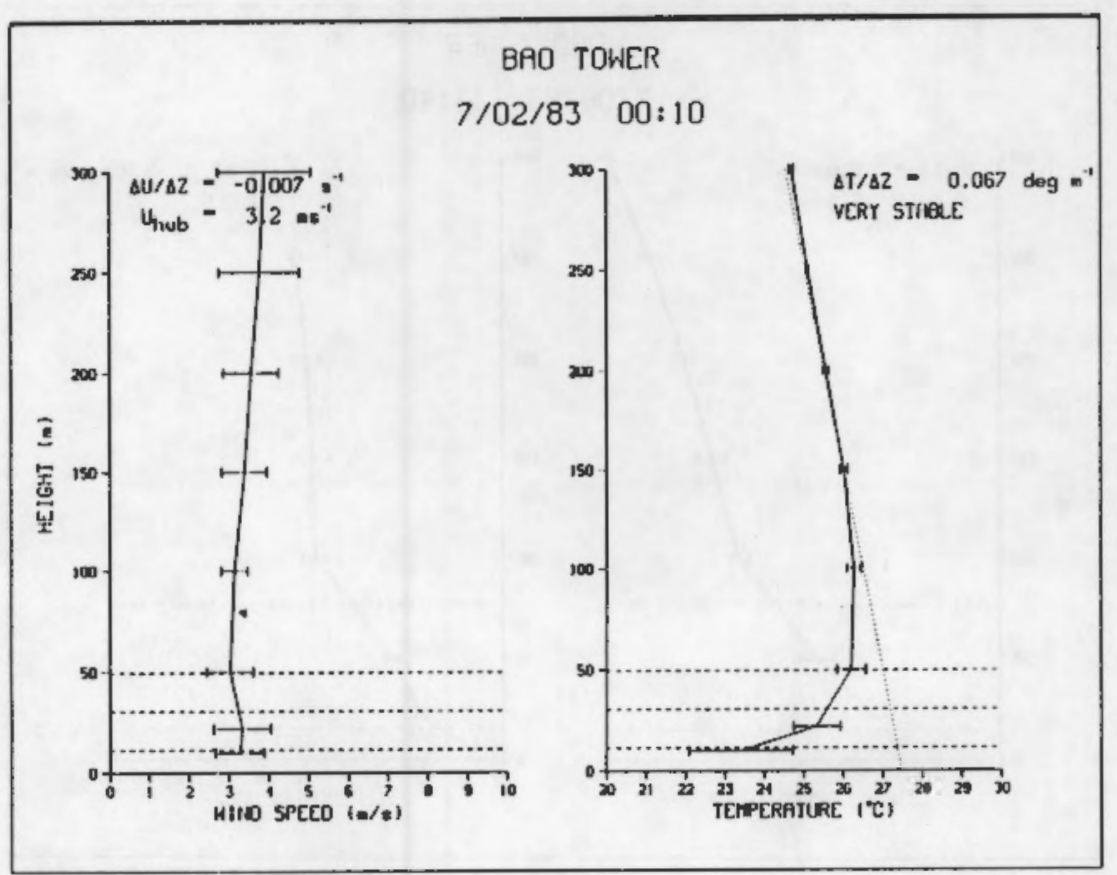

FIGURE 2.3. (contd) 
(a)

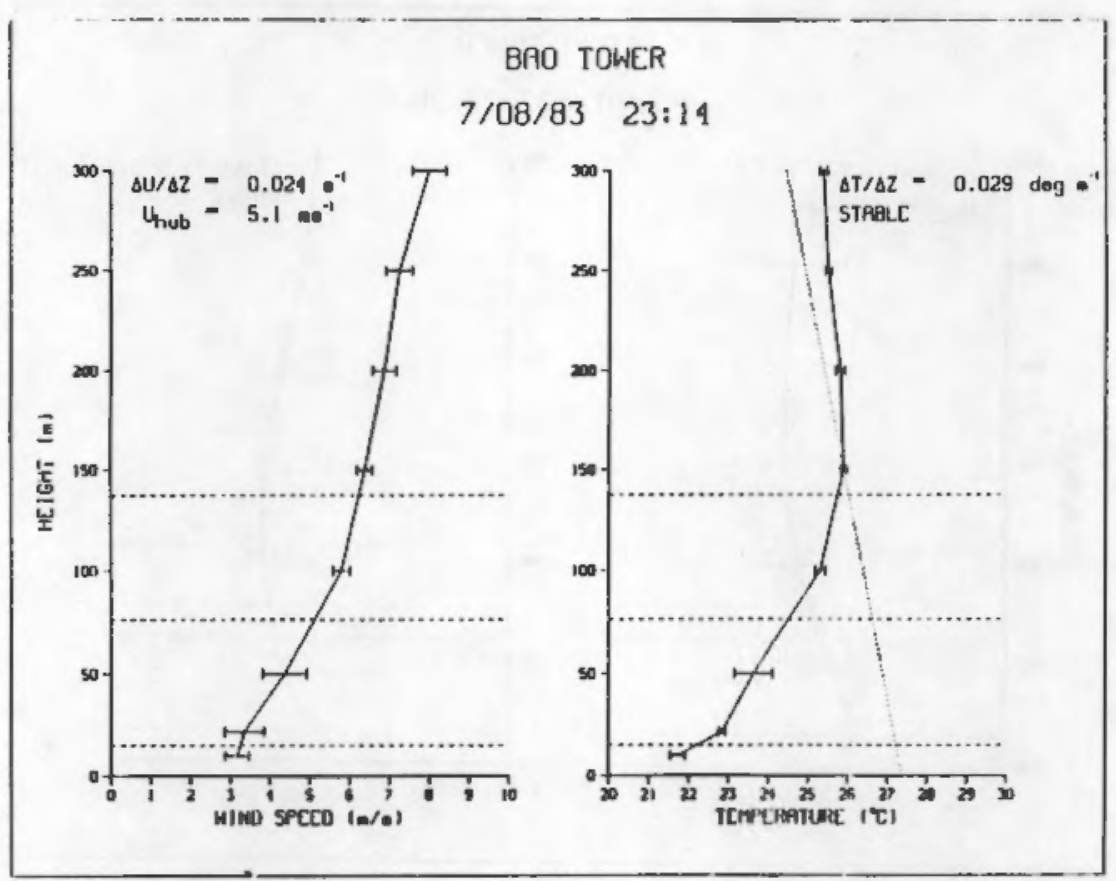

(b)

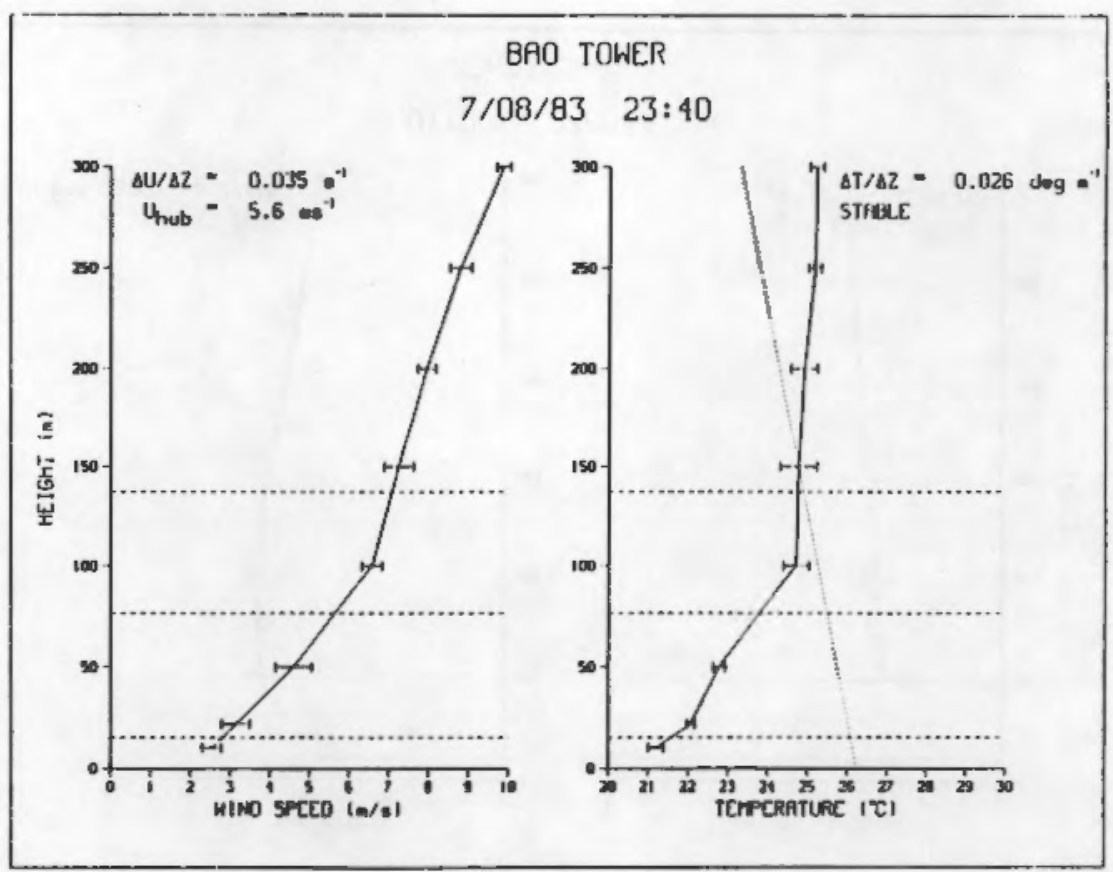

FIGURE 2.4. A More Detailed Description of the Atmospheric Conditions for Each Subcase of Case 3. The plots of vertical profiles of bulk wind speed shear and bulk temperature gradient were derived from measurements made with the NOAA/WPL BAO tower instrumentation. (a) MOD-5B $10 \mathrm{rpm}$, (b) MOD-5B $15 \mathrm{rpm}$, (c) $M O D-2$, (d) $M O D-O A$. 

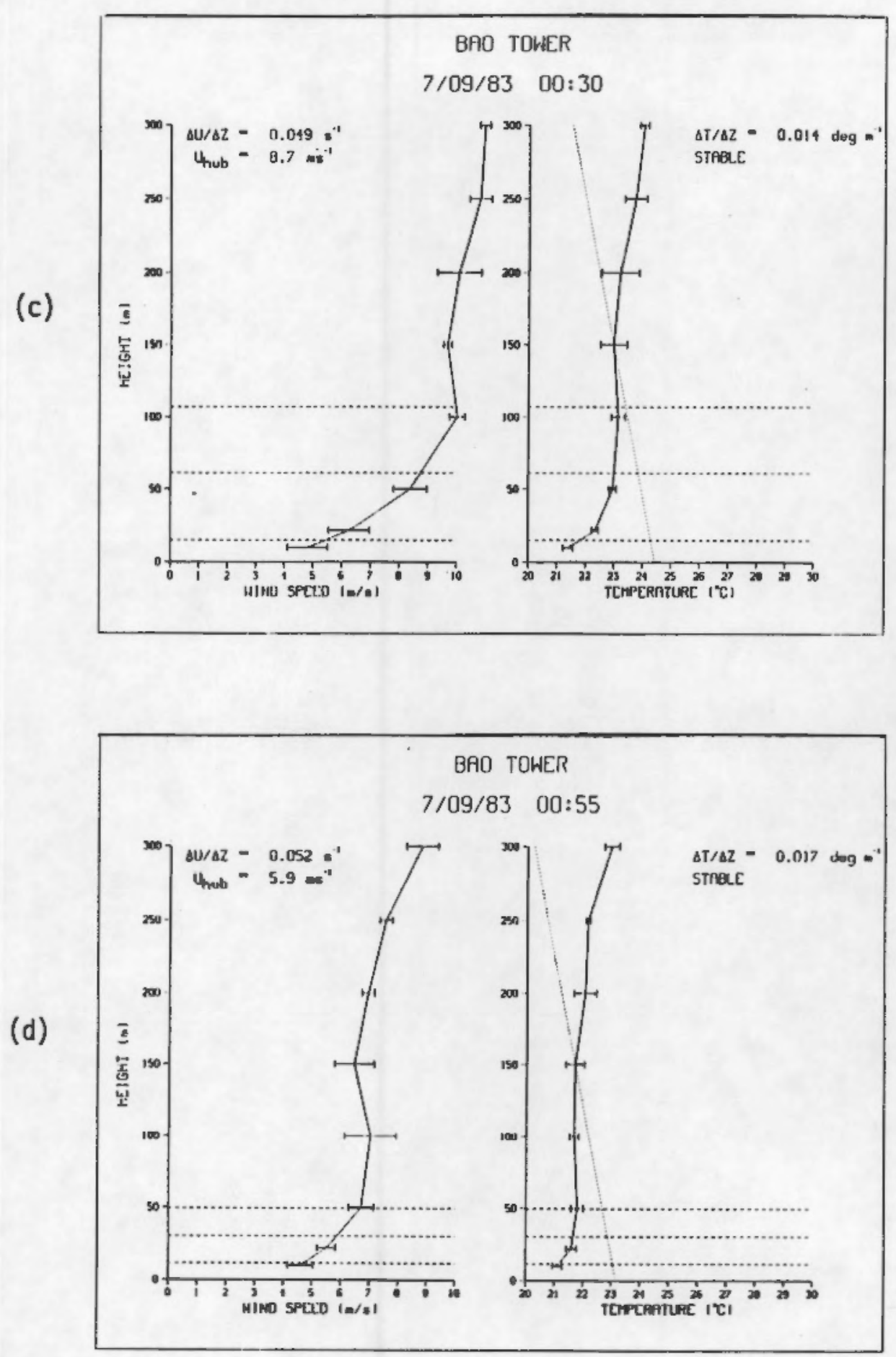

FIGURE 2.4. (contd) 



\subsection{ROTATIONALLY MEASURED WIND USING A DOPPLER LASER}

The lidar-measured rotationally sampled wind data represent an experiment to measure remotely the wind that would be encountered by the outer radial portion of the specified wind turbine blades. The advantage of the method is that it does not require installation of anemometers on a turbine blade or on towers, and it is nonintrusive in the turbine rotor region. At this time the disadvantage is that its accuracy and resolution in space and time are not well known. No suitable comparison of measurements to those made with better known accuracy, such as with a vertical plane array of conventional anemometers, has been made. However, the accuracy and limits in magnitude as a function of fluctuation frequency are well enough known to justify the lidar method's use in a pilot study of the kind reported herein.

A preliminary study was designed by PNL and implemented experimentally by NOAA/WPL using a smaller lidar to demonstrate the concept (Hardesty, Korrell and Hall 1981). In the previous experiment, the data were analyzed with less wind speed resolution than desired, and the laser beam active volume was rotated around a very small circle at too small a rotation rate to represent a wind turbine condition. The results clearly indicated that there might be a significant improvement in the data over that which could be achieved using a single tower with fixed anemometers on it.

\subsection{LIDAR SYSTEM CONSTRAINTS ON THE MEASUREMENTS}

A primary concern is that the volume of air whose velocity is "instantaneously" sensed by the lidar laser beam be of a useful size in relation to the size of the rotor blade. The rotation rate of the blade is the factor that determines whether the lidar system can obtain accurate samples of wind velocity often enough around the circle of rotation to be useful. Previous rotational sampling using measurements from a 12-point ring of anemometers in a vertical plane array provided evidence about the volume of turbulence eddies of importance. From those results it was judged that the lidar would make measurements of the important eddies and be a suitable tool for rotational measurement as indicated below. 
Wind fluctuation spectra are of interest in the present context up to frequencies as high as five times the rotation rate of the simulated wind turbine blade. This requires a minimum of 10 equally spaced samples of wind speed around the circle of rotation. The lidar acquired one useful measure of the along-beam wind speed every $0.05 \mathrm{~s}$. For a rotation period of $1.5 \mathrm{~s}$ (the MOD-OA subcase), a maximum of 30 samples per rotation could be obtained. This provides a spectral resolution to a high frequency of $15 \mathrm{~Hz}$ or 10 times the rotation rate of the blade. Actually only 10 samples per second were taken, allowing a slightly greater amount of laser backscatter data to be accumulated into each sample and giving a slightly better estimate of the wind speed for the sample period.

The laser beam was only a few centimeters in diameter, so the sector of the annulus scanned at the plane of the rotor disk is radially thin (as shown in Figure 3.1 for the MOD-OA subcase). The $0.02-m$ width of the annulus might appear to be rather thin to represent wind over a significant part of the blade. However, two factors modify this interpretation. First, the lidar processing, which results in each single estimate of wind speed from a number

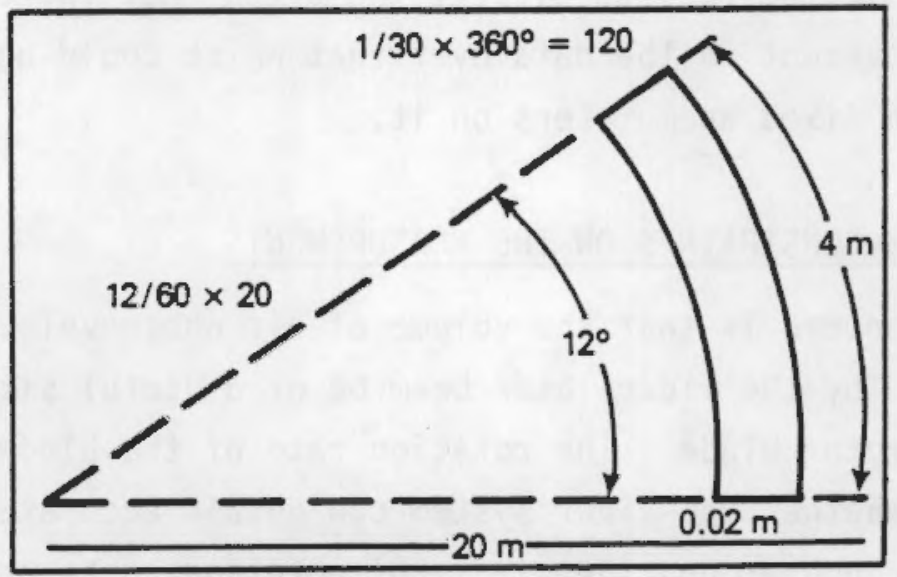

FIGURE 3.1. The MOD-OA Subcase Showing the Geometry of a Scanned Annulus. The laser beam was only a few centimeters in diameter, so the sector of the annulus scanned at the plane of the rotor disk is radially thin. 
of single realizations, provides an average over about $4 \mathrm{~m}$ along the circumference, in the rotational direction $(\theta)$. This is a larger and more significant part of the volume of air through which the rotor passes. If we allow that turbulence eddies have a $\theta$-dimension size that is not radically different from their radial-direction size, the piece of air included in a lidar estimate of speed in an annular sector is more relevant than it would, at a quick glance, have appeared.

The second factor is the size of the active sensing volume of the laser beam. A look at the along-beam active sensing length raises the question of whether the lidar measures the turbulence with too much smoothing because of the weighted spatial integration inherent in the continuous-wave lidar technique. The sensing part of the beam may be considered to be an ellipsoidal volume, elongated in the beam axis direction. The length of this volume, $\Delta R$, in these experiments varied with the radius of the turbine from one subcase to another as indicated in Column 8 of Table 2.1.

A brief exploration of the beam volume problem will be instructive (see Figure 5.1). For the MOD-OA subcase, the active volume length is only about 0.2 rotor diameter $(\Delta R=7 \mathrm{~m}$; see Column 9$)$ and is about the same as the extent in the circumferential direction, $\Delta C(4 \mathrm{~m})$. However, as the scanned diameter, $D$, increases to those for larger turbines, $\Delta R$ increases to a maximum of $0.6 \mathrm{D}$. It turns out that this is all right for the analyses we have in mind, as we shall show next. Previously, in the analyses of vertical plane array data (Connell and George 1987), the 38-m-diameter ring of 12 anemometers extended across volumes that were about $1 \mathrm{~m}$ in diameter. However, the anemometer smoothes the high-frequency part of the wind velocity measurement to represent the average over a distance of about $5 \mathrm{~m}$ because of the lagging response of the propeller, shaft, and generator system. In the vertical plane array experiments, we found in addition that a running mean of the measured Eulerian time series from each anemometer, which eliminated the fluctuations from eddies smaller than $50 \mathrm{~m}$, made little change in the resulting rotationally sampled wind speed spectrum. The exception was that the troughs between the harmonic bands at multiples of the rotation frequency in the spectrum were deeper. 
In the absence of definitive tests that vary the length of the active portion of the laser beam while keeping the same rotation diameter, on the basis of the arguments presented above, the extended active beam length is assumed to be acceptable for the purpose of the type of experiments performed. The accuracy of the lidar may be less than desired to match the results of a complete vertical plane array, but there appear to be no absolutely negating factors related to the active beam volume geometry.

\subsection{ROTATIONAL TIME SERIES AND SPECTRA FROM LIDAR MEASUREMENTS}

Graphs of fluctuations of wind speed for 10 revolutions of each turbine of Case 1, measured with the scanning lidar, are shown in Figure 3.2. Take caution in comparing the five graphs for the different wind turbines, because the wind conditions did not remain the same and the time scales are different from graph to graph. Nevertheless one can see in the top two curves for the MOD-5B that increasing the rotation rate tends to put a greater relative amplitude of fluctuation into the variation. In the bottom two graphs the variations are for smaller-diameter turbines and increasing rotation rates. The relative amount of high-frequency fluctuation increases.

The details in the effect are more clearly seen in the spectral density curves for 13.6-min intervals shown in Figure 3.3. The character of the band structure of the spectrum at multiples of the rotation frequency (labeled along the abscissa) changes in a clear way from turbine to turbine. Also the more continuous aspect of the spectra changes in a distinct way. The spectra for the other two wind conditions are shown in Figures 3.4 and 3.5. Substantial changes in rotational wind character according to turbine type and also according to the basic wind condition are obvious. 

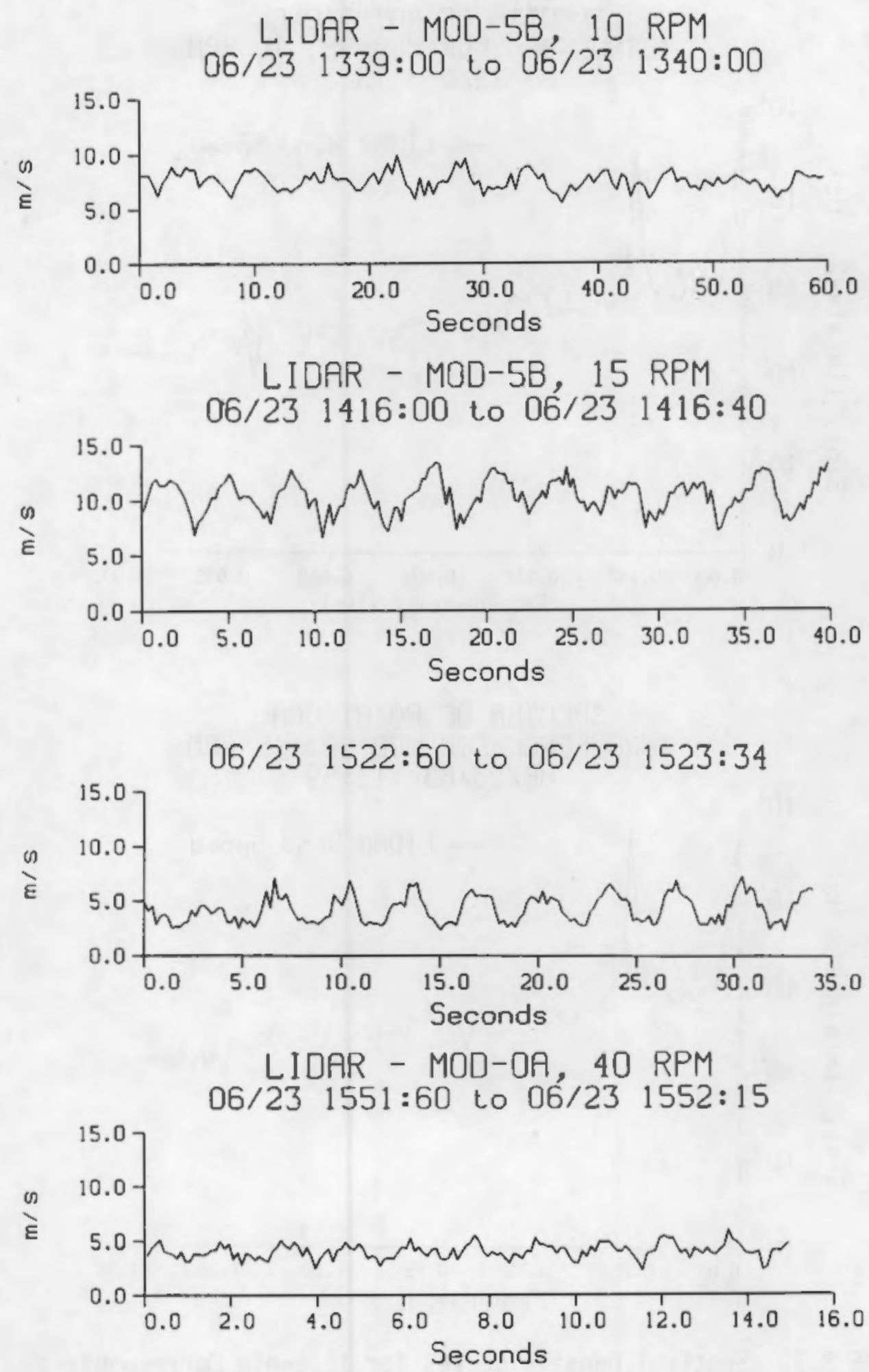

FIGURE 3.2. Graphs of Fluctuations of Wind Speed for 10 Rotations, Measured with the Scanning Lidar for Case 1 Hind Conditions 
SPECTRA OF ROTATIONAL

TURBULENCE FOR MOO-5B, 10 RPM

$06 / 23 / 83 \quad 13: 37$

(a)

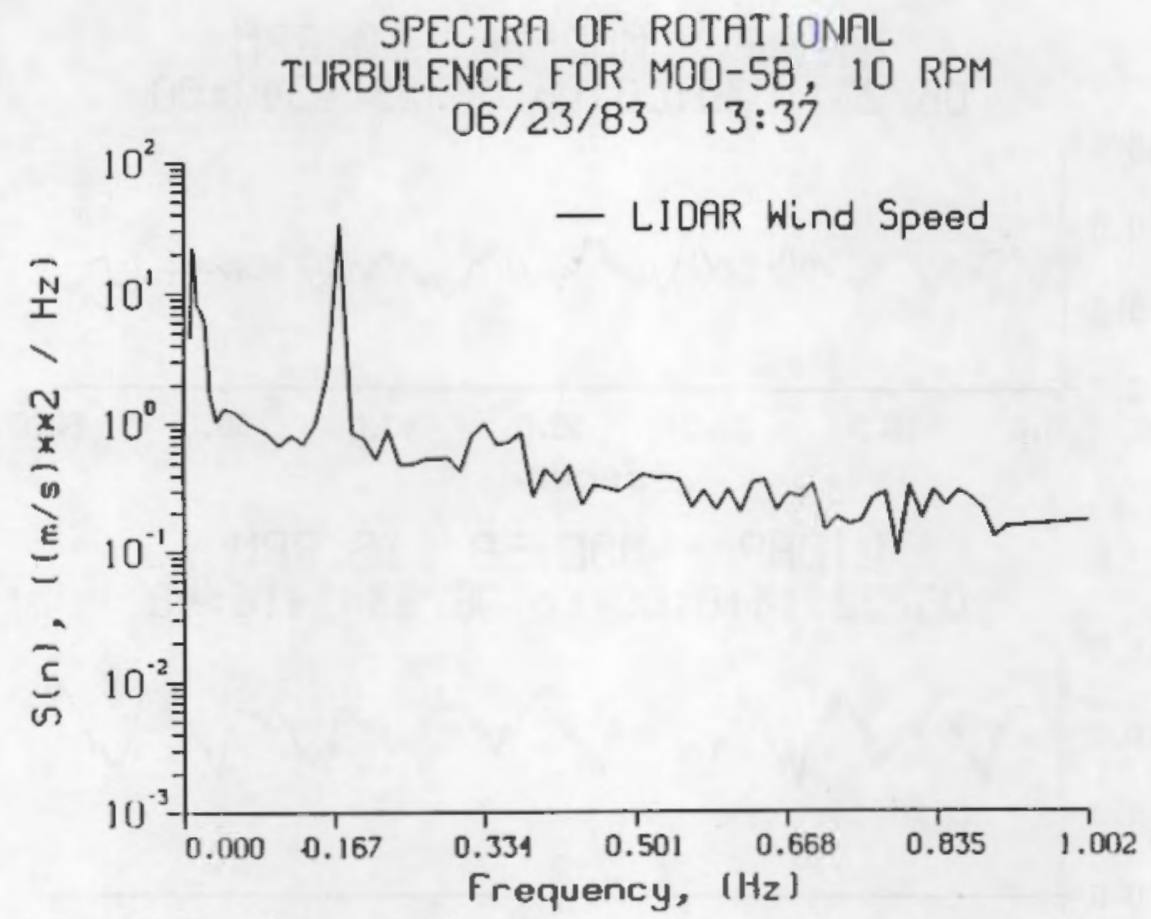

(b)

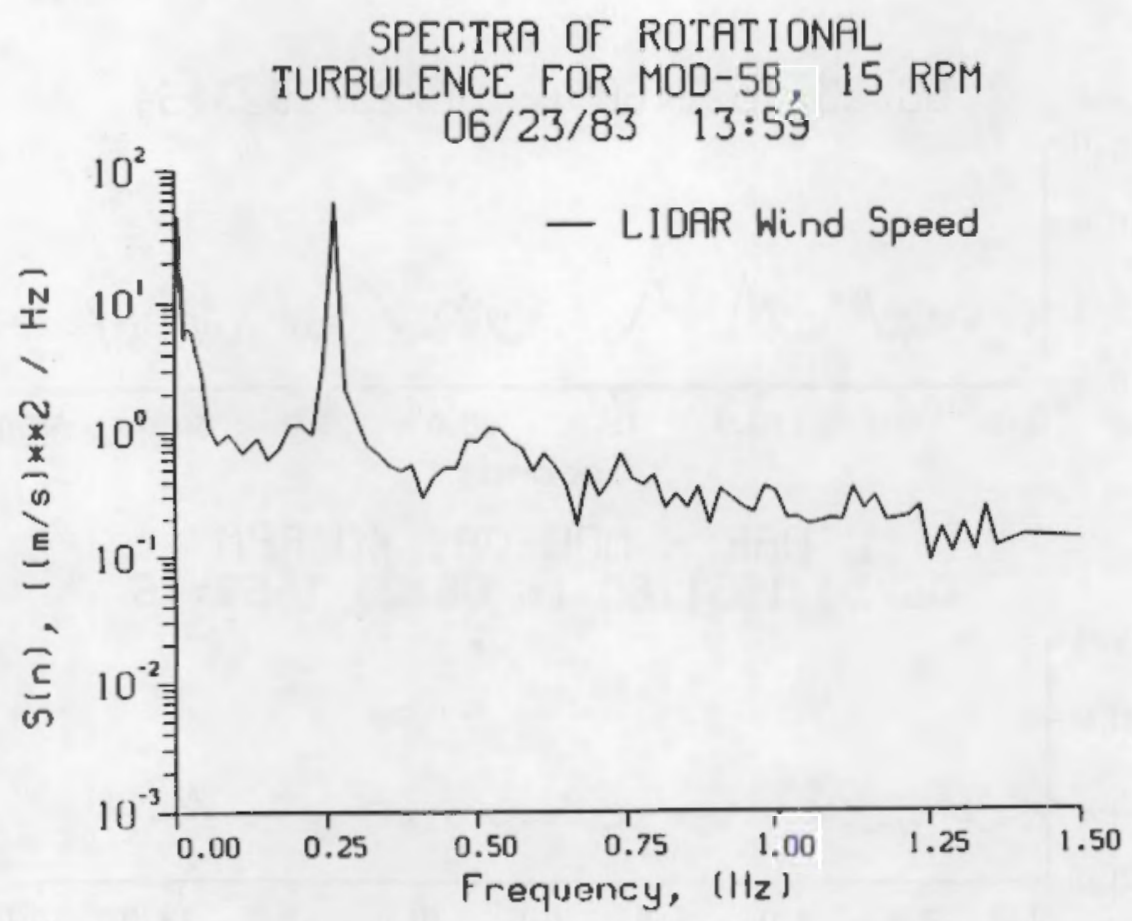

FIGURE 3.3. Spectral Density Curves for 13.6-min Corresponding to the Case 1 Time Series Shown in Figure 3.2. The spectral density is plotted on a logarithmic scale, and the frequency is plotted on a linear scale. 

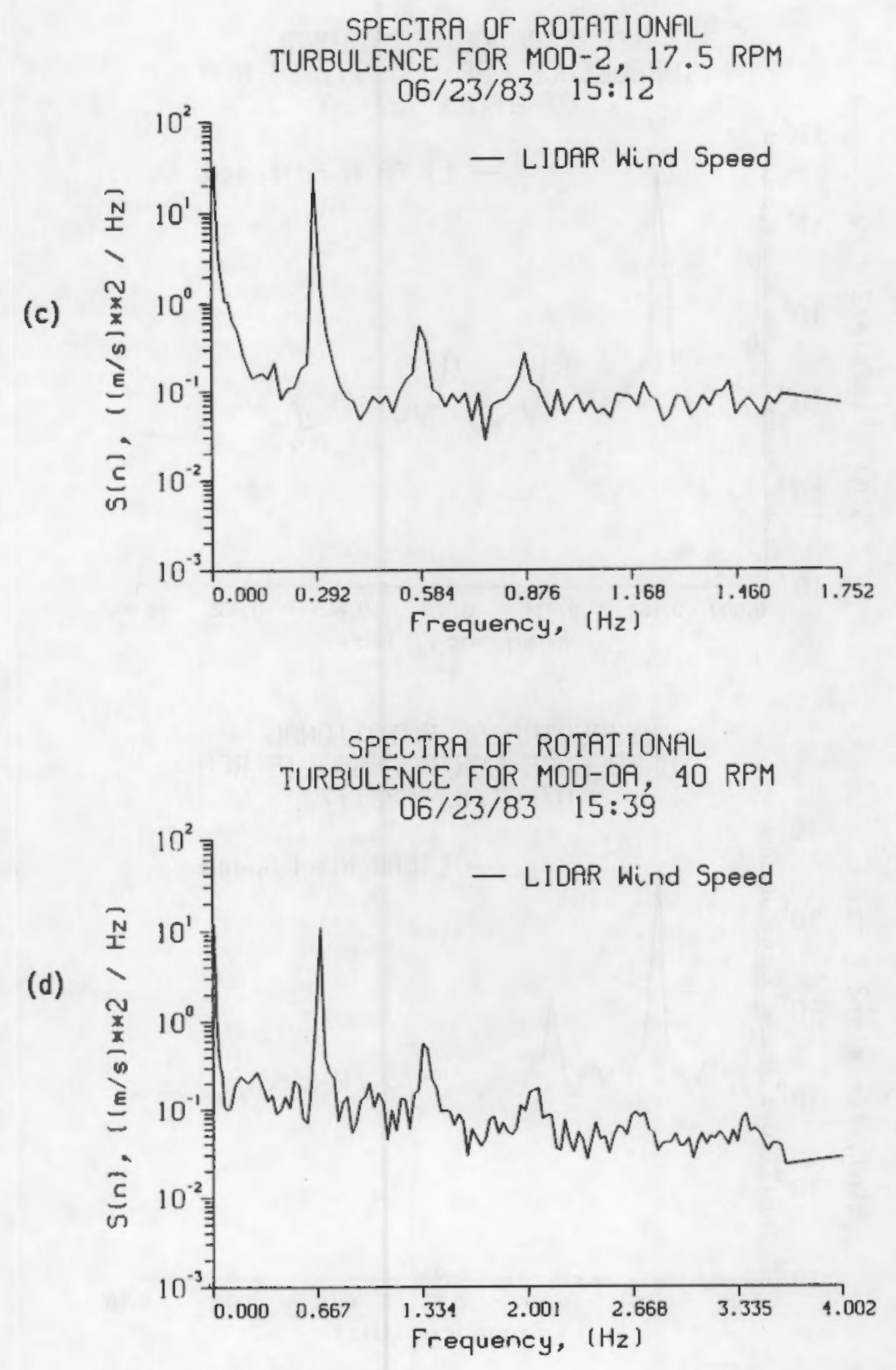

FIGURE 3.3. (contd) 
(a)

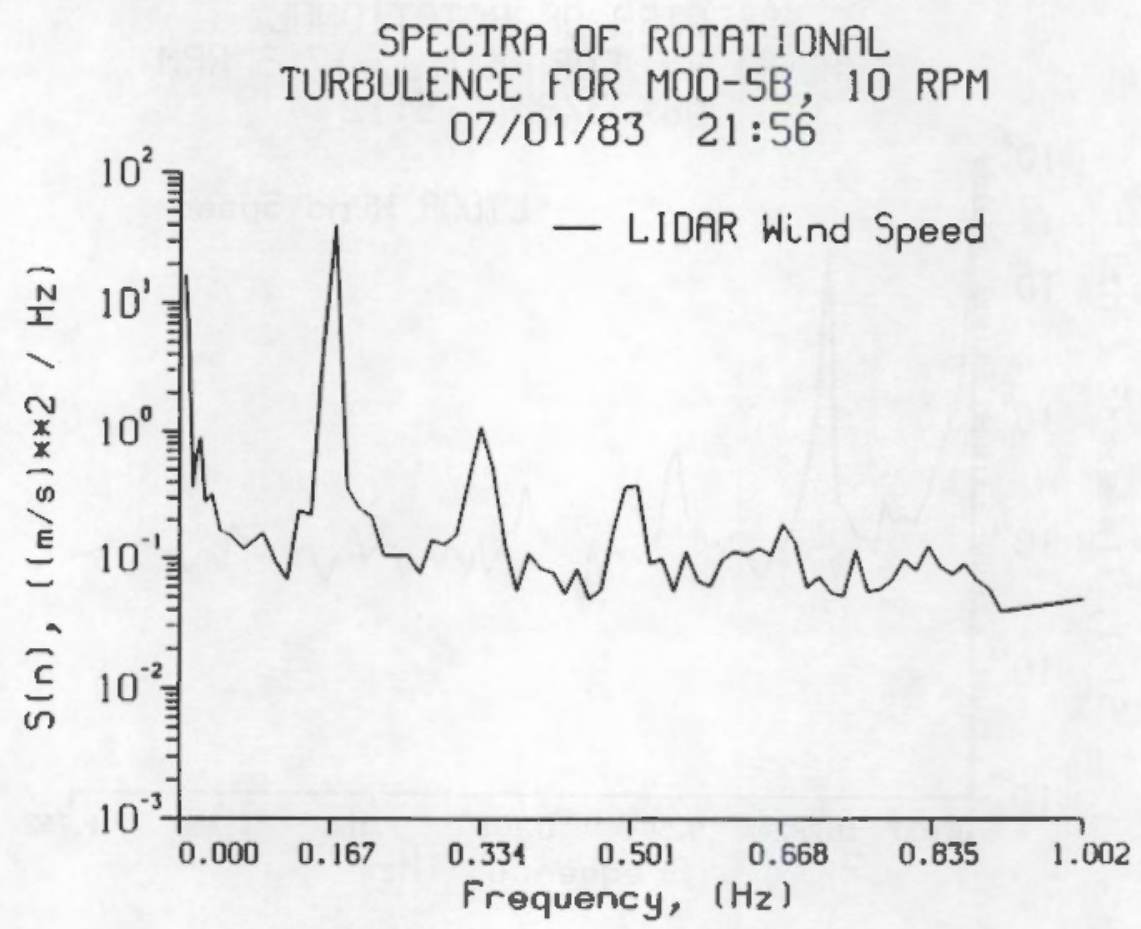

(b)

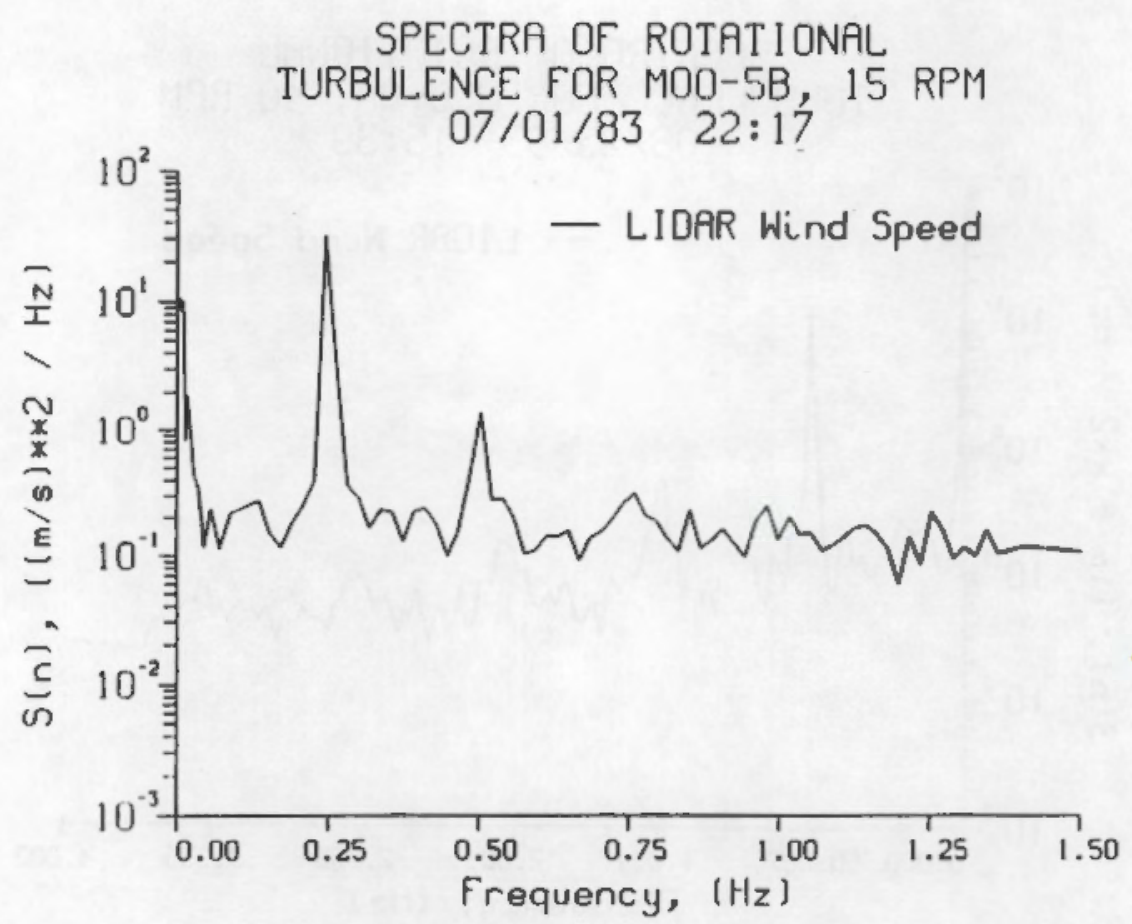

FIGURE 3.4. Spectral Density Curves for $13.6 \mathrm{~min}$ Corresponding to the Case 2 Time Series Shown in Figure 3.2. The spectral density is plotted on a logarithmic scale, and the frequency is plotted on a linear scale. 

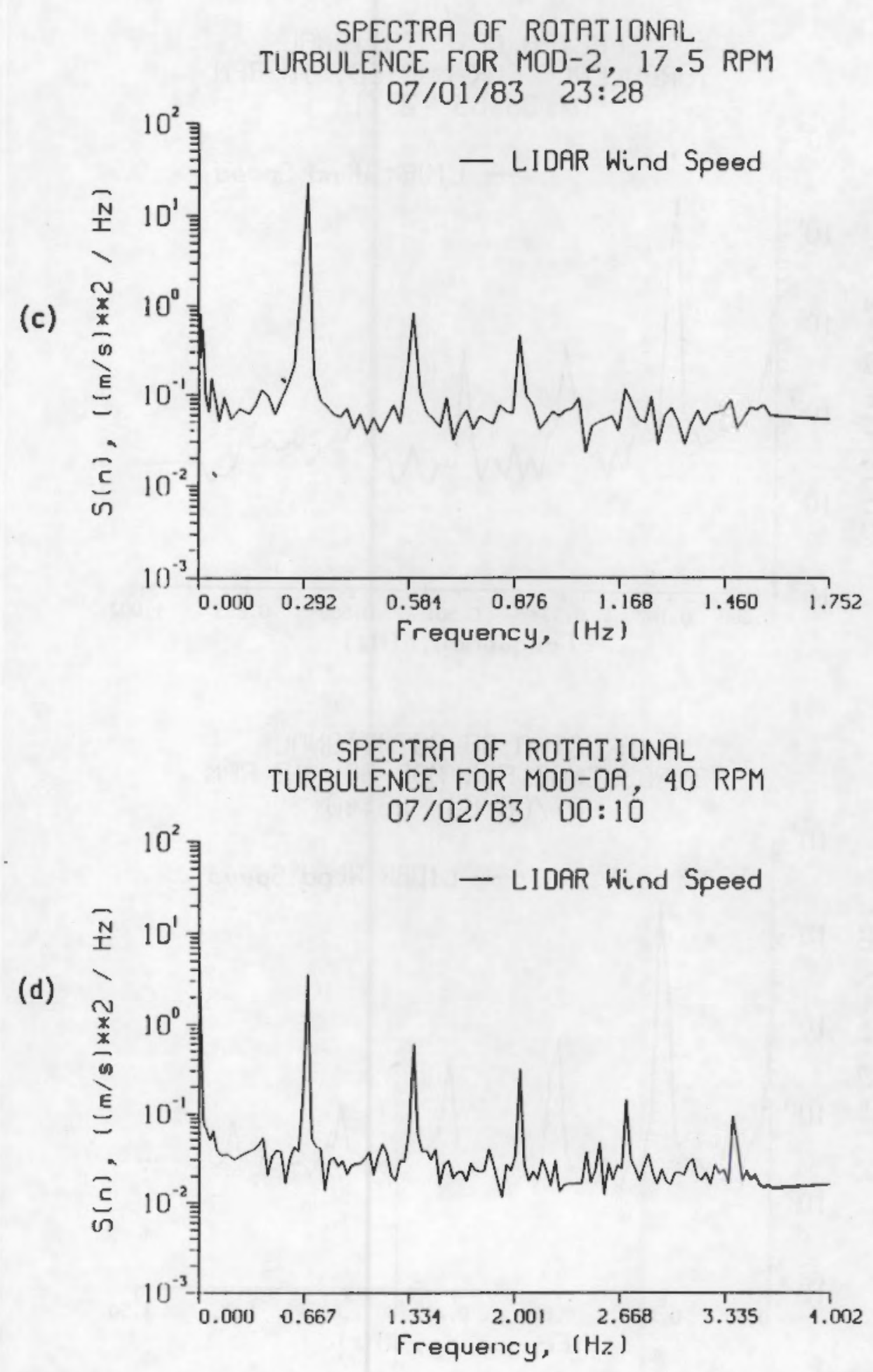

FIGURE 3.4. (contd) 
SPECTRA OF ROTATIONAL

TURBULENCE FOR MOO-5B, 10 RPM

$07 / 08 / 83 \quad 23: 14$

(a)
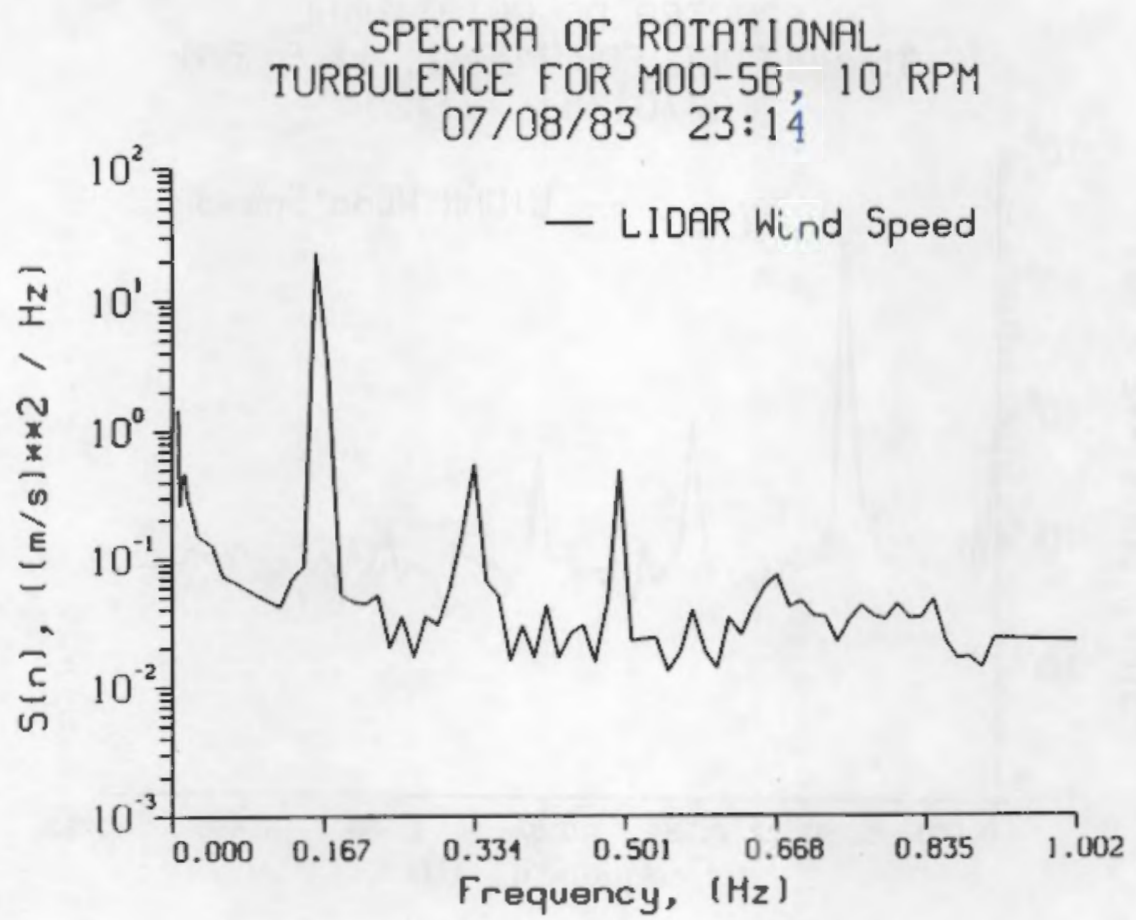

(b)

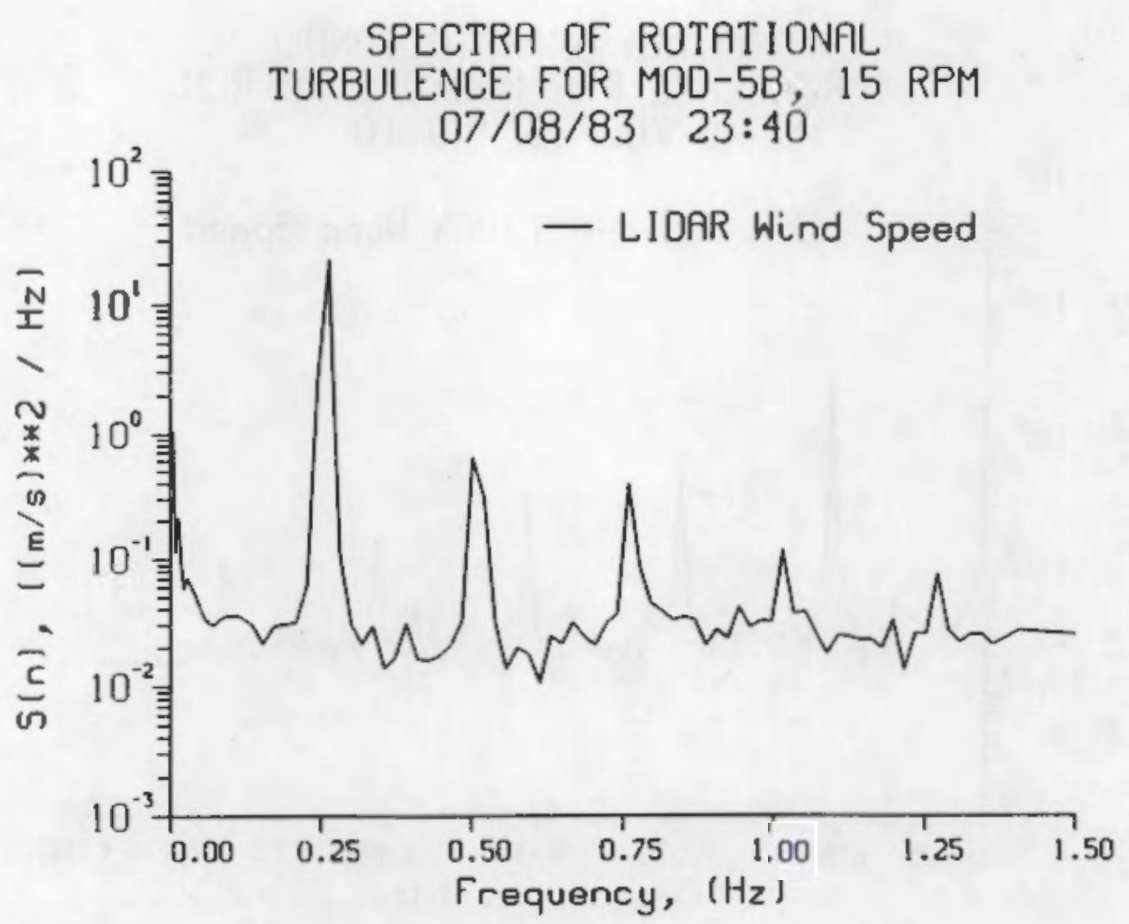

FIGURE 3.5. Spectral Density Curves for 13.6 min Corresponding to the Case 3 Time Series Shown in Figure 3.2. The spectral density is plotted on a logarithmic scale, and the frequency is plotted on a linear scale. 

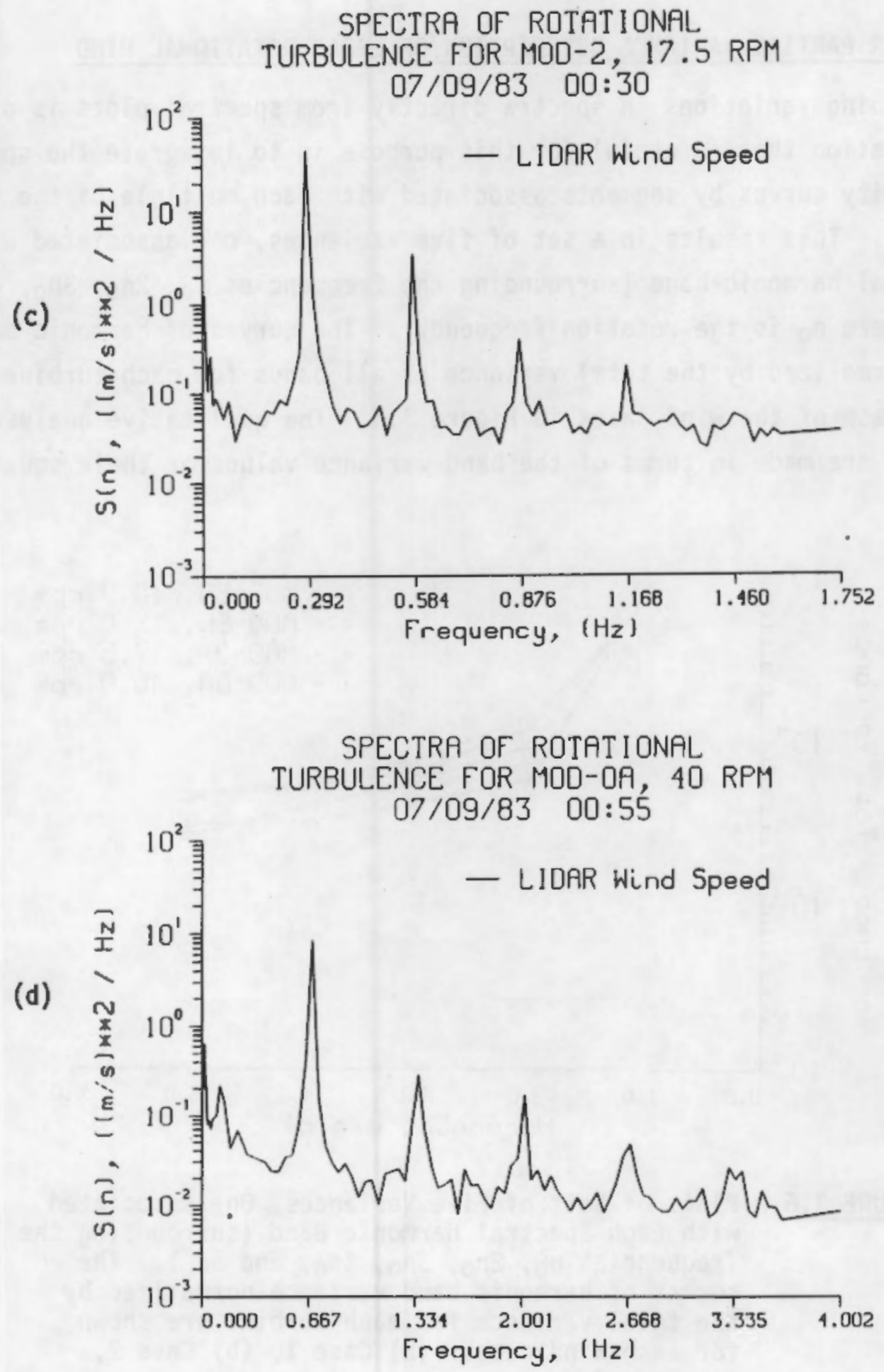

FIGURE 3.5. (contd) 


\subsection{BAND OR PARTIAL VARIANCE DESCRIPTION OF LIDAR ROTATIONAL WIND}

Describing variations in spectra directly from spectral plots is difficult. A simplification that is useful for this purpose is to integrate the spectral energy density curves by segments associated with each multiple of the frequency of rotation. This results in a set of five variances, one associated with each spectral harmonic band (surrounding the frequencies $n_{0}, 2 n_{0}, 3 n_{0}, 4 n_{0}$, and $5 n_{0}$, where $n_{0}$ is the rotation frequency). The curves of harmonic band variance normalized by the total variance of all bands for each turbine are shown for each of the wind cases in Figure 3.6. The qualitative analyses in this report are made in terms of the band variance values or their square roots.

(a)

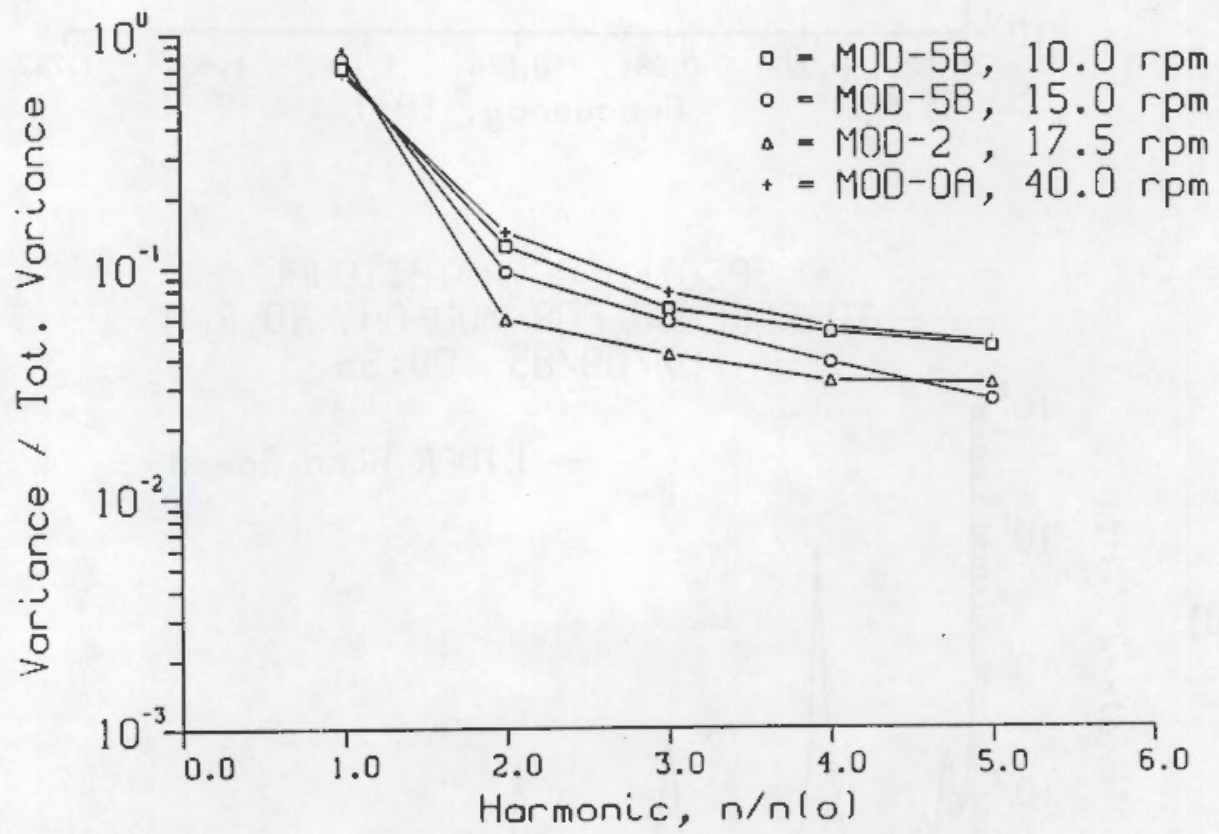

FIGURE 3.6. Plots of Sets of Five Variances, One Associated with Each Spectral Harmonic Band (surrounding the frequencies $n_{0}, 2 n_{0}, 3 n_{0}, 4 n_{0}$, and $\left.5 n_{0}\right)$. The curves of harmonic band variance normalized by the total variance for each turbine are shown for each wind case: (a) Case 1, (b) Case 2, (c) Case 3 . 

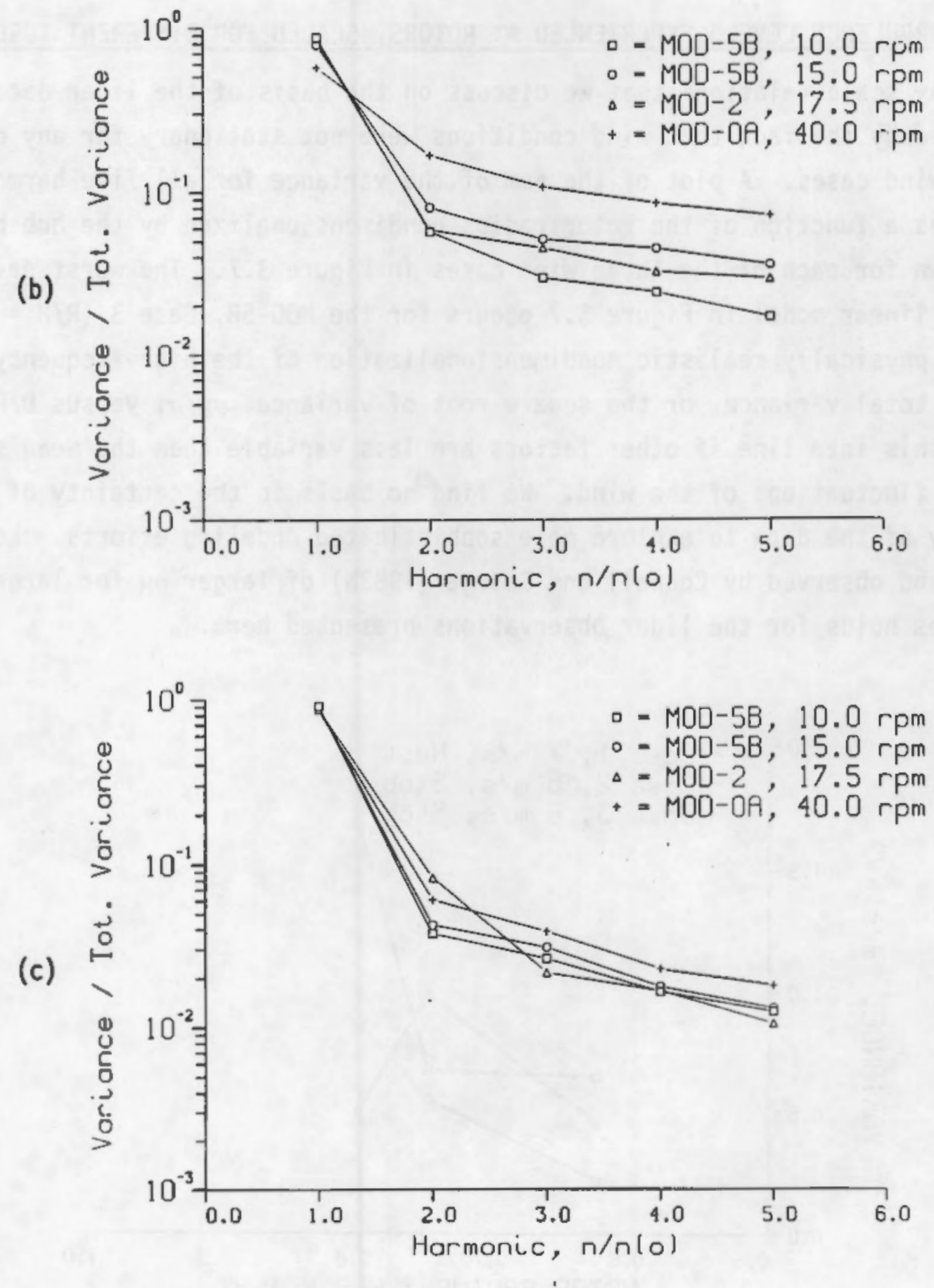

FIGURE 3.6. (contd) 


\subsection{TURBULENCE LEVELS EXPERIENCED AT ROTORS, SCALED FOR DIFFERENT TURBINES}

Any scale relations that we discuss on the basis of the lidar data are weakened by the fact that wind conditions were not stationary for any of the three wind cases. A plot of the sum of the variance for all five harmonic bands as a function of the rotor radius nondimensionalized by the hub height is shown for each of the three wind cases in Figure 3.7. The worst deviation from a linear model in Figure 3.7 occurs for the MOD-5B, Case $3(R / H=0.8)$. A more physically realistic nondimensionalization of the high-frequency variance by the total variance, or the square root of variance, $\sigma_{H} / \sigma \mathrm{T}$ versus $\mathrm{D} / \mathrm{H}$, might bring this into line if other factors are less variable than the mean square of the fluctuations of the wind. We find no basis in the certainty of the quality of the data to explore more sophisticated modeling efforts. Loosely, the trend observed by Connell and George (1983b) of larger of for larger wind turbines holds for the lidar observations presented here.

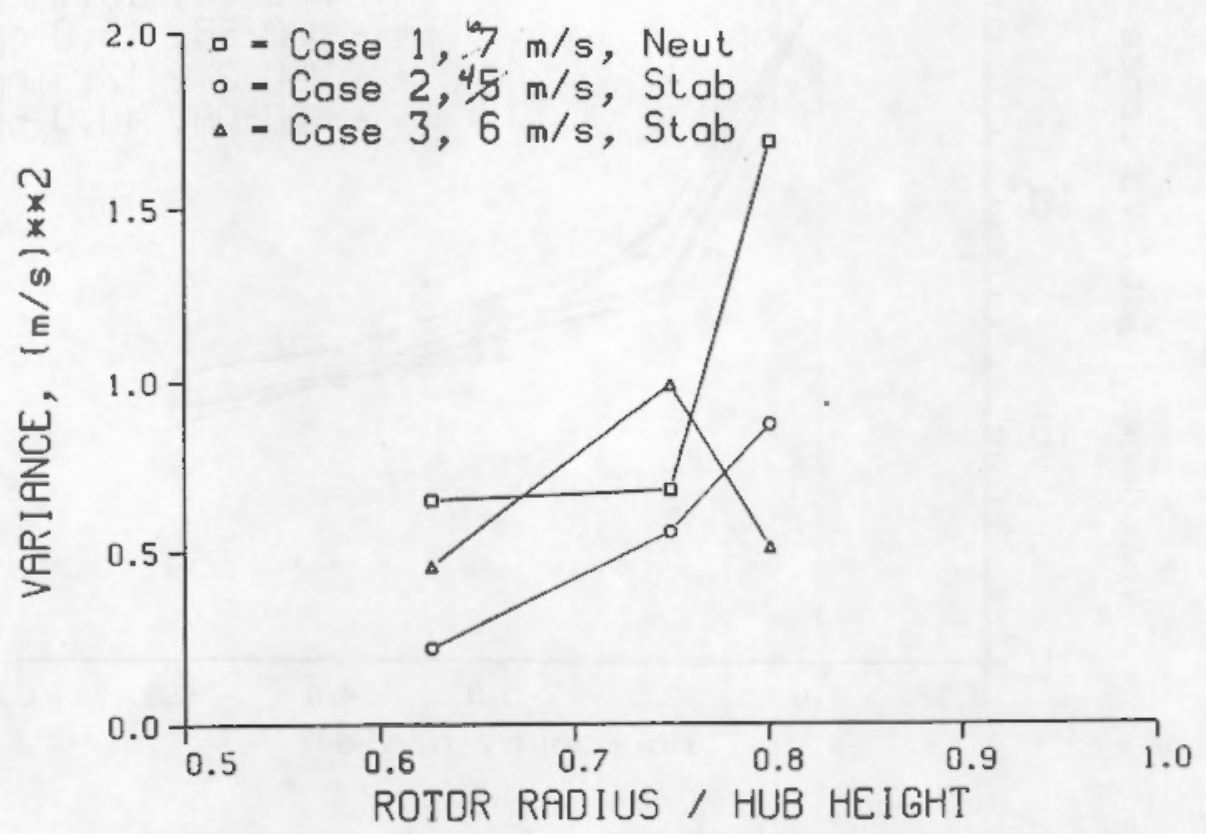

FIGURE 3.7. A Plot of the Sum of the Variance for All Five Harmonic Bands as a Function of the Nondimensional Rotor Radius, R/H, Where $H$ is the Hub Height, for Each of the Three Wind Cases 
The tendency of rotational measurement to put greater portions of the $\sigma_{i}$ into the higher $n_{j}$ region as rotation rate increases and the blade radius and hub height remain the same is also demonstrated weakly. That this effect is seen at all is a qualitative statement that some of the high-frequency, smaller-amplitude turbulence is measured with the lidar. Possible improvements of the lidar real-time processing hardware promise to increase the accuracy and resolution of measurements of the higher frequency components of turbulence. (a)

(a) Hardesty, NOAA/WPL, personal conversation. 



\subsection{SIMULATION OF THE ROTATIONALLY SAMPLED WIND AROUND A CROSSWIND CIRCLE USING MEASUREMENTS WITH ANEMOMETERS ON A SINGLE METEOROLOGICAL TOWER}

Several other studies (Connell and George 1983b; Connell et al. 1988; Connel1, Morris and Hinchee 1987) have resulted from the development and testing of a model for simulating the rotationally measured wind velocity using conventional turbulence measurements at a few heights on a single tower. The mode1, STRS-2, was used to make the first estimates of the turbulent wind characteristics, using wind measurements that would be experienced by largeto-very-large turbines. Because the NOAA/WPL BAO tall meteorological tower was used to support the mirror that scanned the lidar beam active volume around circles for the measurements reported in the last section, single-tower measurements were available for comparing the lidar method to the STRS-2 method. Both methods are of uncertain accuracy but less accurate than the rotational sampling of a many-point (say, 10 or more points) vertical plane array of anemometers on a crosswind circle.

In this report, neither the lidar nor the STRS-2 result is considered to be a standard against which to compare the other. The emphasis of the present section is on the results of STRS-2 at times that correspond to parts of the three lidar cases for which there were sonic anemometer turbulence data measured at the tower concurrent with lidar measurements. Not all subcases will be represented by the STRS- 2 simulation because the sonic anemometers were not always functional.

A time series of STRS-2 simulated rotationally sampled wind speed for Subcase $2 c$ (the MOD-2, $17.5 \mathrm{rpm}$ subcase) is shown as a solid line in the graph of Figure 4.1. The hub-height wind at a nonmoving point (the Eulerian wind speed) is also drawn on the graph as a dashed line. The fluctuations in the STRS-2 wind far exceed those observed at a single point. The time series shown is plotted for 10 revolution periods of the rotor blade. The variation of the wind speed caused by the rotation through the mean wind shear and a like frequency caused by the turbulence can be identified as a large component of the variation in the time series. 

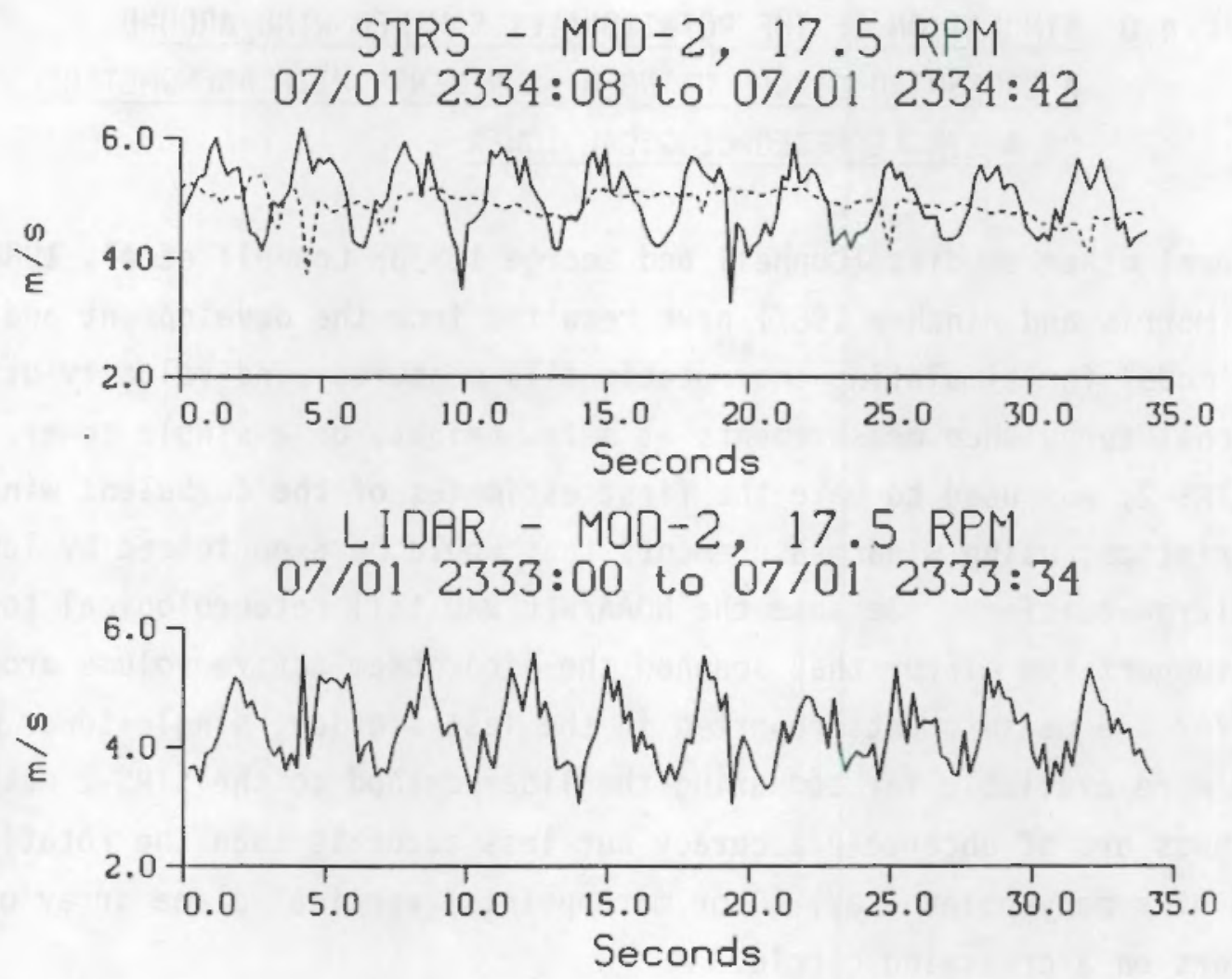

FIGURE 4.1. A Time Series of STRS-2 Simulated Rotationally Sampled Wind Speed for Subcase c (the MOD-2, $17.5 \mathrm{rpm}$ ) of Wind Case 2, Shown as a Solid Line in the Upper Graph. The hub-height wind at a motionless point (the Eulerian wind speed) is also drawn on the graph as a dashed line. The corresponding lidar wind is shown in the lower graph.

The STRS-2 time series may be compared to the corresponding lidar rotationally measured time series shown in the bottom graph in Figure 4.1. The start time of the STRS-2 time series is about 2 min later than for the lidar to account for the approximate time required for the turbulent air sensed by the lidar to arrive $322 \mathrm{~m}$ downstream at the meteorological tower (see Table 2.1, column 7 , row 3 ). There are substantial differences between these two time series. The details of the time series would not be expected to remain the same unless the variations of wind speed of the air were truly frozen and the fluctuations in time were caused by advection of the spatial structure past the anemometers at the mean speed of the wind. The frozen turbulence hypothesis is not a reasonable approximation to real turbulence when 
the separation is as large as $322 \mathrm{~m}$ ! However, the simple statistic of the standard deviation of the two fluctuating time series measured at the two locations is the same for both models, $\sigma_{u}=0.58$ to $0.59 \mathrm{~m} / \mathrm{s}$. The mean wind speeds differ by about $0.5 \mathrm{~m} / \mathrm{s}$. This is probably caused by the error in the absolute value of the lidar measurements, a result of instrument bias.

The turbulence spectra of the STRS-2-modeled winds are shown in Figures 4.2 and 4.3. They generally appear to follow the trend of the corresponding lidar spectra (Figures 3.3 and 3.4 ) in the high-frequency region, starting slightly below the frequency of rotation of the rotor blade (indicated by the leftmost spike on the spectral plot graphs). At this 1-P frequency the two methods give nearly identical results. But at higher frequencies, the STRS-2 spectrum appears to show less energy than does the lidar spectrum. A similar partial loss in high-frequency replication of rotationally sampled wind relative to the rotationally sampled wind from the full crosswind vertical plane array has been observed in separate tests of the STRS -2 model. The STRS-2 model

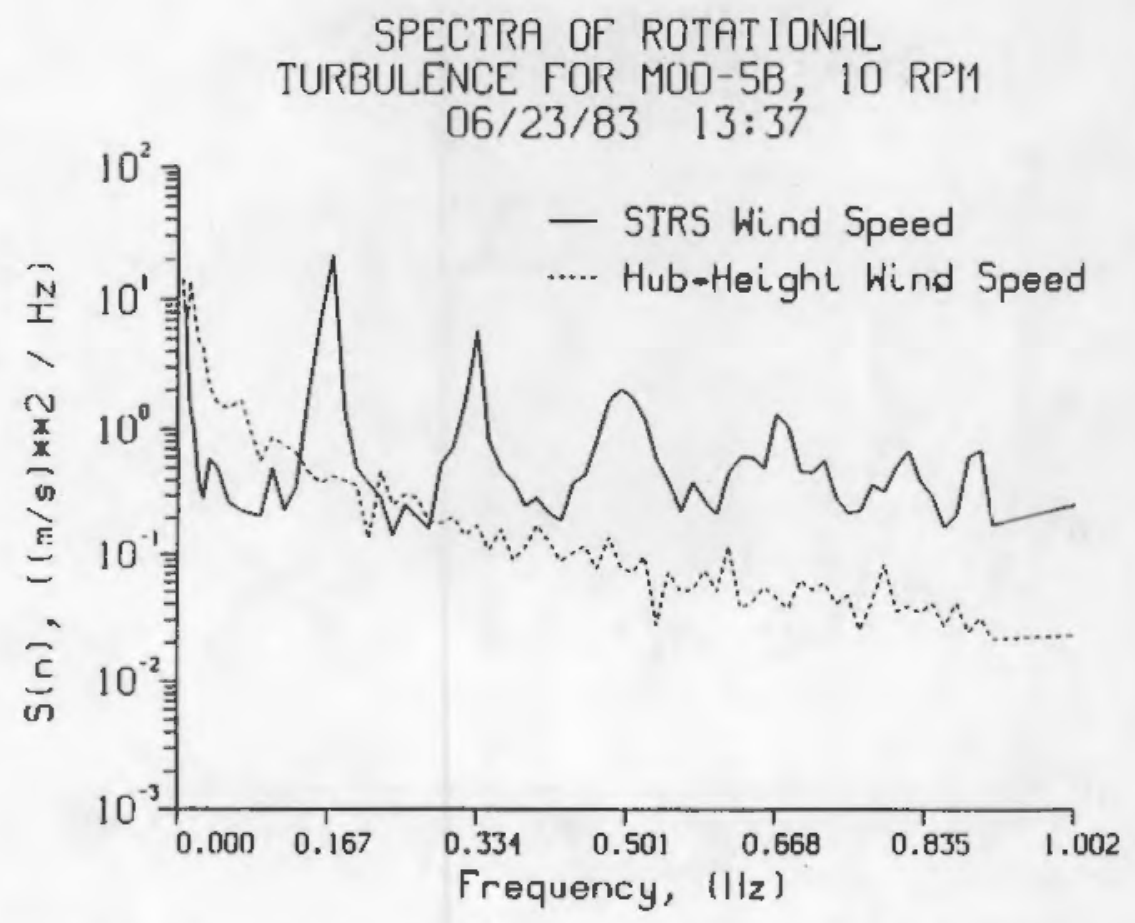

FIGURE 4.2. The Turbulence Spectra of the STRS-2-Modeled Winds, Case 1. The Eulerian hub-height wind is shown as a dashed line. 

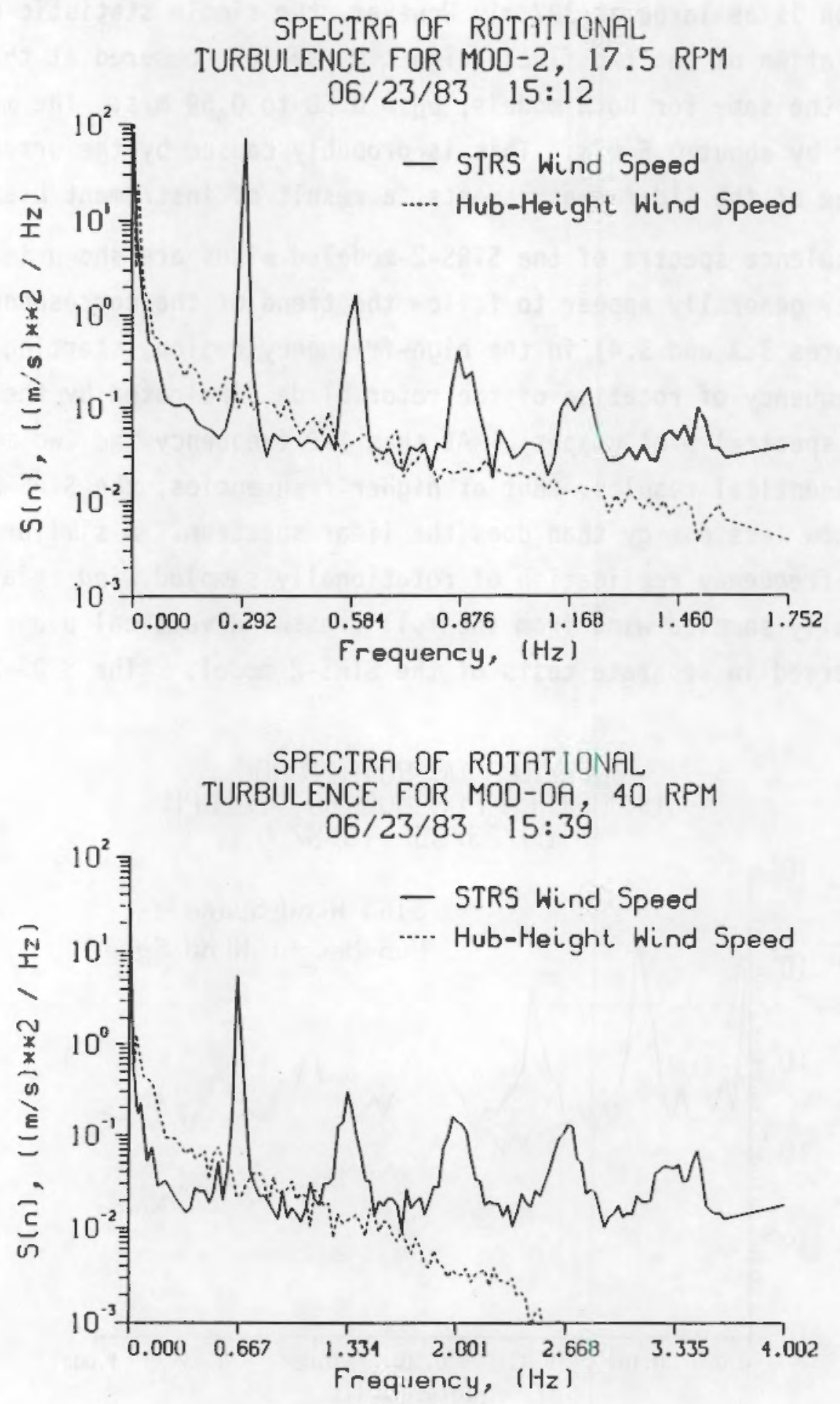

FIGURE 4.2. (contd) 

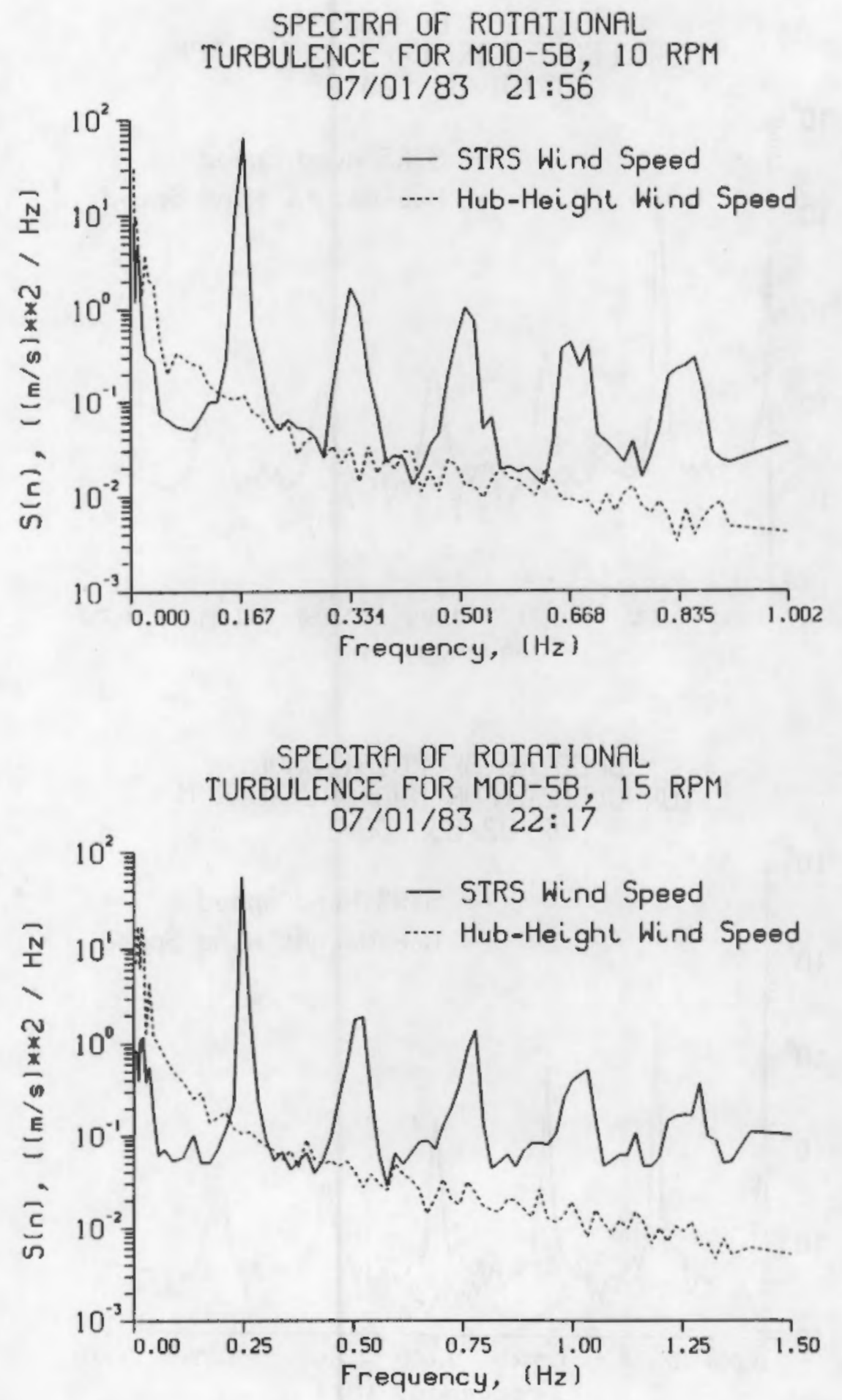

FIGURE 4.3. The Turbulence Spectra of the STRS-2-Modeled Winds, Case 2. The Eulerian hub-height wind is shown as a dashed line. 

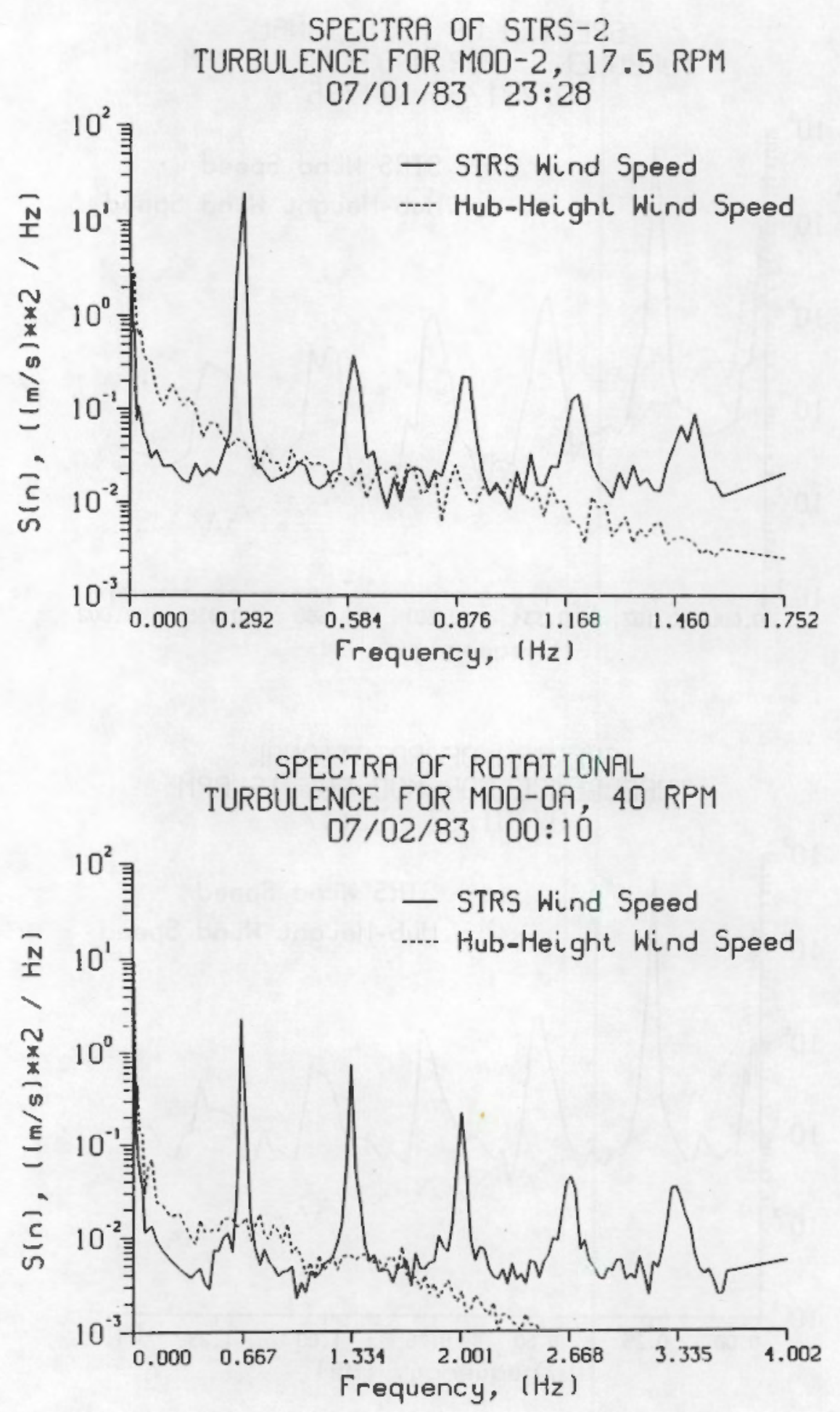

FIGURE 4.3. (contd) 
is known to replicate the lower frequency portions of the spectral results using a full vertical plane array, which, as shown in Figures 4.2 and 4.3, are asymptotic to the Eulerian spectra (dashed lines). Comparison of the STRS-2 spectra with lidar-measured wind spectra shows that the lidar substantially underestimated the low-frequency portion of the rotationally sampled wind spectrum.

Because of the complexity of detail of the spectra, visual inspection of them may not convincingly yield a simple relationship. To make the data more amenable to quantitative analysis, as with the lidar spectra, band variances are computed. These band variances, $\left(\sigma_{j}\right)^{2}$, normalized by the total variance of all bands, associated with each multiple of the sampling (or simulated blade) rotation rate are plotted as a function of the nondimensional center frequency of each band, $n_{i} / n_{0}$, in figure 4.4. All of the subcases corresponding to the $17.5 \mathrm{rpm} \mathrm{MOD-2}$ turbine, for both the lidar-measured and the STRS-2simulated wind, are included in the graph. The general trends described above
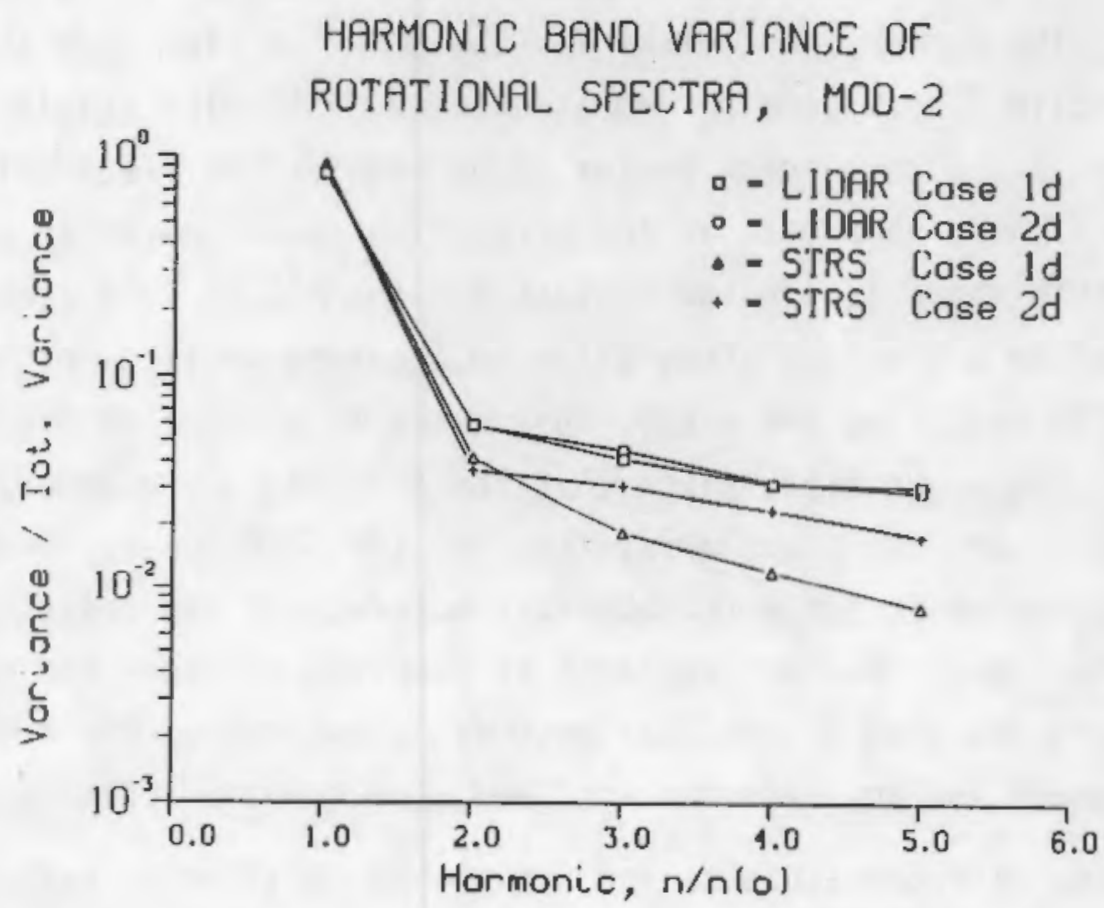

FIGURE 4.4. The Nondimensional Band Variances, $\sigma i{ }^{2} / \Sigma \sigma_{i}^{2}$, Associated with Each Multiple of the Sampling (or simulated blade) Rotation Rate, Plotted as a Function of the Nondimensional Center Frequency of Each Band, $n_{j} / n_{0}$. 
from observing the detailed spectra in Figures 4.2 and 4.3 are borne out by this more precise analysis. Generally, the STRS-2 simulation appears to be most deficient at frequencies greater than $n_{j} / n_{0}=2$.

The STRS-2 method is useful in estimating the rotationally sampled wind in the crosswind plane when only measurements along a single vertical line are available. A correction factor might be acceptable in some cases for adjusting the energy so simulated in the spectral frequency range of $n / n_{0}=2$ to 5. Some estimates of these correction factors could be made in the present study if we could accept the lidar data as of reference quality. However, that is a bold step more suitably made if one could first refine and calibrate a lidar system against a more completely known reference wind speed measurement, such as that made using a vertical plane array of conventional anemometers in a circular ring. Such a calibration and comparison opportunity has not occurred.

In Figure 4.5 we use the lidar as a reference and plot correction factors for the STRS-2 at the BAO site for the wind conditions occurring during the measurements. The correction factors for the MOD-2 in wind Case $1 \mathrm{~b}$ are indicated by the solid line. Case 1, representing a statically stable atmosphere, shows a larger STRS-2 correction factor to be required at frequencies greater than $n / n_{0}=2$. There is a peak in the correction factor curve at $n / n_{0}=3$. The shape of this curve is similar to that for the MOD-OA in a stable atmosphere, obtained in a previous study using an accurate vertical plane array for rotationally measuring the wind. This curve is plotted in Figure 4.5 as a dashed line. We might extrapolate that the lidar data are more like the data from a full vertical plane array than are the STRS-2 data, although we have no data by which to judge the absolute accuracy of the rotational measurements by the lidar. Further research is required to learn the absolute accuracy of both the STRS-2 and lidar methods in describing the rotationally sampled wind speed for any selected wind and wind turbine situation.

For studies of rotor dynamics and fatigue in relation to turbulent winds, the lidar method appears to be more suitable than STRS-2 for estimating the rotationally measured wind at the rotor blade. This is not only because 


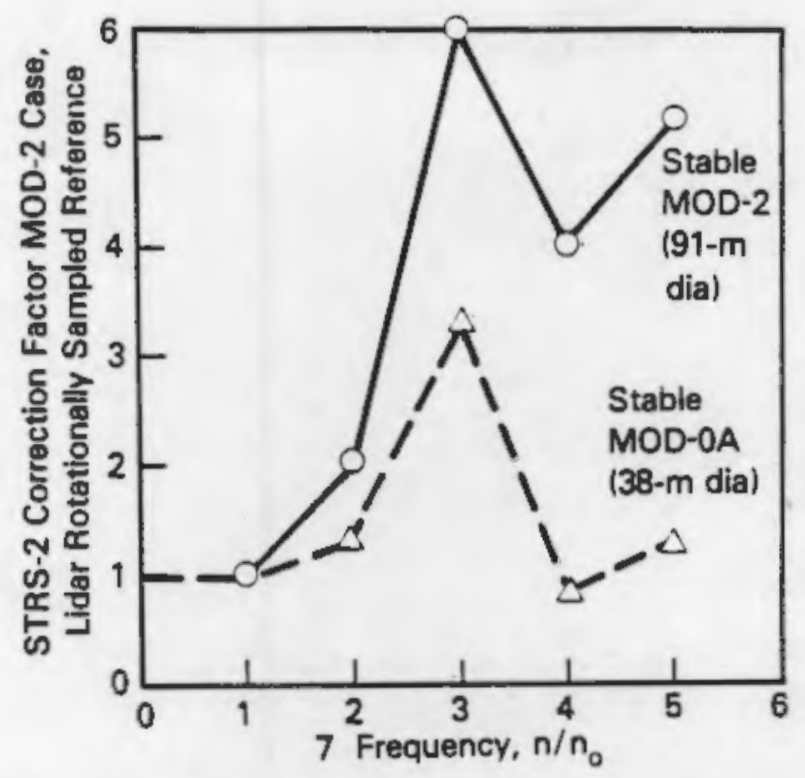

FIGURE 4.5. A Plot of Correction Factors for STRS-2 at the BAO Site for the Wind Conditions Occurring During the Measurements, Using the Lidar Measurements as the Standard. The correction factors for the MOD-2 in wind Case 1 are indicated by the solid line. The curve for the MOD-OA in a stable atmosphere, obtained in a previous study using an accurate vertical plane array for rotationally measuring the wind, is plotted as a dashed line.

the lidar actually measures by scanning around the crosswind circle, but because the measurement volume may be placed close to the rotor blade without installing equipment there.

It appears that the lidar may be a suitable tool for estimating turbulence magnitudes at a single radial location of a rotor blade when a nonintrusive, nontower method of measurement near the rotor is required. However, if lidar is to become a tool to be used in characterizing the microscale wind, a few hardware data processing improvements would be helpful. Further, its calibration against a vertical plane array of conventional anemometers rotationally sampled concurrent with the laser rotational measurement must be undertaken. 



\subsection{FURTHER DISCUSSION OF ACCURACY AND APPLICABILITY OF LIDAR AND SINGLE-TOWER METHODS OF ESTIMATING THE ROTATIONALLY MEASURED WIND SPEED}

The accuracy of the measurement and analys is schemes used for both the lidar and the STRS-2 methods of characterizing the wind involve several additional factors not previously discussed. These factors help explain the basis for the concluding remarks and recommendations made in Chapter 6.

\subsection{ACCURACY OF THE STRS-2 METHOD}

The underlying restriction on the accuracy of the winds characterized using the STRS-2 method may be stated as follows: turbulence is so essentially three-dimensional and has such substantial random aspects that the variation of the instantaneous flow field throughout a crosswind plane cannot be determined from turbulence measurements at a set of locations on a single vertical line. Nevertheless, STRS-2 is designed to estimate the character of the wind at locations around a vertical crosswind circle by synthesizing the crosswind variation using measurements of the turbulent wind speed from several points on a single tower.

Various users have wanted the STRS-2 model for purposes well beyond its original intended purpose, which was to make a best possible quick estimate of the character of the rotationally measured wind speed that would be experienced by wind turbines having rotor diameters ranging from about $75 \mathrm{~m}$ to $120 \mathrm{~m}$ and having a variety of hub heights. The only test of the method was made using a full vertical plane array for a circle of rotation that had a diameter of $39 \mathrm{~m}$. This does not provide a strong basis for scaling the model for large wind turbines.

The main fact that favors the STRS-2 model is that it utilizes measured wind time series that at least partly characterize specific real sites. Further, a time series of rotationally measured wind speed, derived from the measured wind values, is the primary output of the STRS-2 model. The use of real wind values to build a rotational time series is for some purposes more valuable than the crosswind completeness of the theoretical spectral model. This point may be particularly important for complex terrain wind sites, for 
which theoretical models of the rotationally sampled wind are not yet known to give representative results. The error in the STRS- 2 method may be estimated by looking at the correction factors (the inverse of the error) shown in Figure 4.5. A more complete discussion of error is given in the PNL report by Connell et al. (1988).

Although the spectral statistic of STRS-2 usefully represents the character of turbulence around a ring, the time series it produces does not appear to be an accurate representation of the detailed time series of the rotationally sampled instantaneous time series of wind speed from the full vertical plane array circle. Another method of rotationally measuring the wind velocity without requiring a crosswind planar array of anemometers is to support one or two hotfilm anemometers from rotor blades, but it requires access to each wind turbine of concern. The rotational measurement by the scanning lidar beam is a less intrusive alternative that may produce a time series with more correct detail. We discuss the lidar accuracy more fully in Section 5.2, based on information from NOAA/WPL (Kardesty, Korrell and Hall 1981; Hardesty et al. 1981; Hardesty and Weber 1984; and unpublished interim contractor reports).

\subsection{ACCURACY OF THE ROTATIONALLY SCANNING LIDAR}

In this experiment, coherent infrared light was emitted by the laser in a continuous-wave beam. Measurement of the component of wind velocity along the beam axis depended upon detection and Doppler-shift frequency analys is of infrared radiation scattered directly back by aerosols in the object volume viewed by the detector and its optics. Use of the continuous-wave mode limited the active measuring region to that part of the beam within the depth of focus about the focal point of the detecting telescope. The laser beam was about 1 to $2 \mathrm{~cm}$ wide and passed through a path of air 100 to $400 \mathrm{~m}$ long to the point of focus, depending upon the turbine diameter being matched. The principles of the measurement technique are discussed in greater detail below.

Aerosols in all parts of the beam scatter the beam energy. This can be a factor in accuracy of estimation of wind speed. Too little aerosol in the atmosphere will allow a long range of beam penetration, but provide little light scattered directly back to the lidar detector. Too much aerosol will scatter the beam so extensively that inadequate beam energy will reach the 
range of interest or too small a fraction of light scattered directly back to the detector will have come directly back from the selected target volume. Typically, the aerosol content of the atmosphere will have an acceptable concentration for the rotational measurement of wind at a wind turbine rotor. Thus it is possible to discuss the target volume of the beam as determined by the telescope optics. A sketch of the resulting active beam volume shape is shown in Figure 5.1. The scattered light return from the active volume is weighted in favor of the center of the active volume by the telescope. The weighting makes the active volume behave as though it were a prolate ellipsoid.

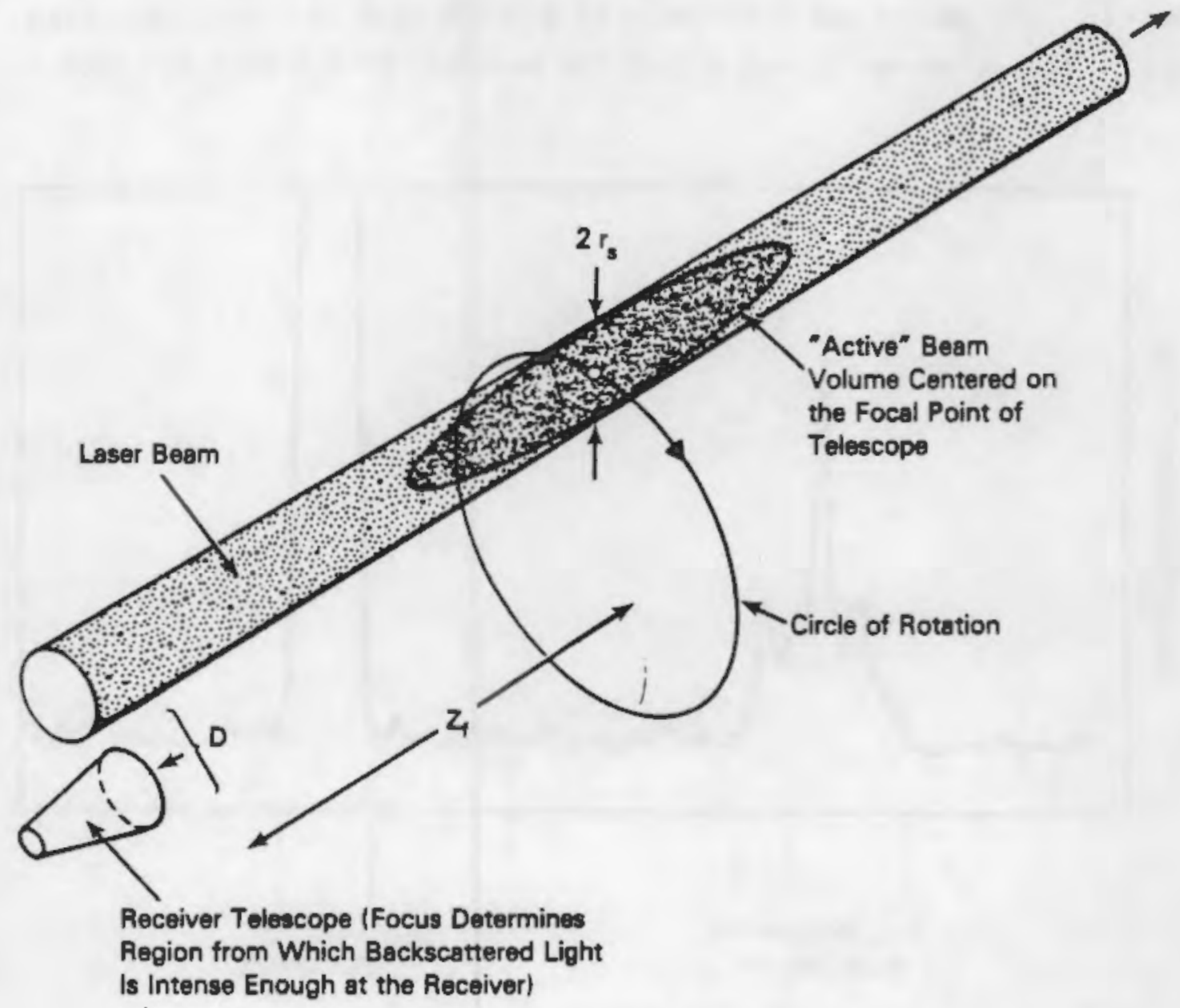

FIGURE 5.1. A Sketch of the Lidar Beam Illustrating the Active (target) Volume Beam Shape Determined by the Lidar Receiver Telescope Optics 
The rather long active volume means that there will be variations in the velocity of air and aerosols in it. This will result in a spectral band distribution of Doppler frequency shifts in the received light. Because the objective is to have a single estimate of the average velocity of the target volume of air, consider how the lidar analysis assigns a single value to the spectrum of speeds. An example of the receiver output Doppler frequency shift spectrum (corresponding to a speed spectrum) is shown in Figure 5.2 for a small fraction of the time of one rotor blade rotation.

The scheme selected for obtaining a suitable single speed from the distribution of speeds labeled $A$ in Figure 5.2 will in part determine the errors of estimation. The amount and uniformity of distribution of light-scattering aerosol in the volume will also affect the accuracy of the estimate from

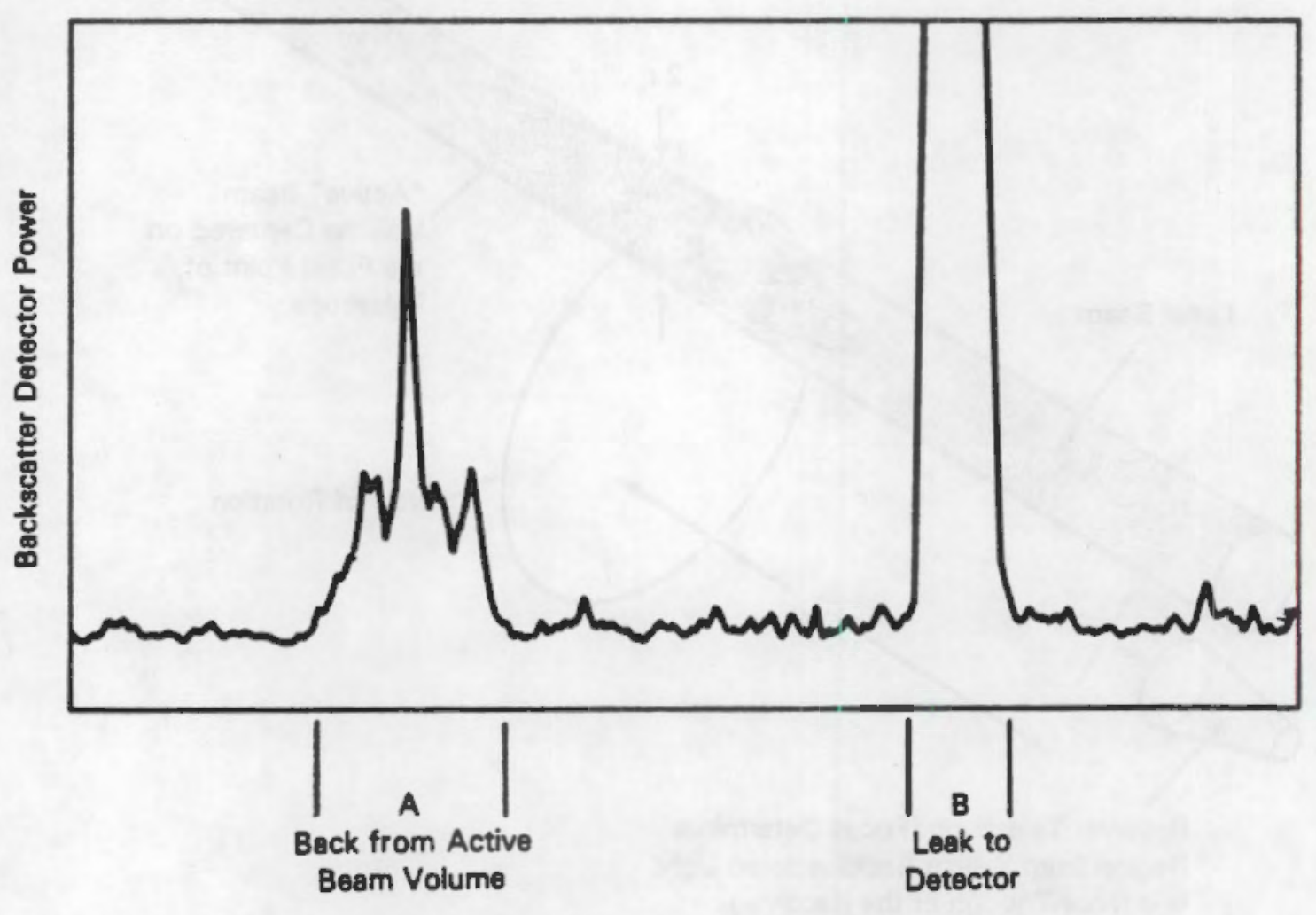

Speed or Doppler Shift Frequency

FIGURE 5.2. An Example of the Doppler Frequency Shift Spectrum of Receiver Output Voltage (corresponding to a speed spectrum) for a Small Fraction of the Time of One Rotor Blade Rotation 
Spectrum A. In part, the aerosol content and the active volume size determine how long a scattered return must be accumulated to produce a reliable spectral estimate. Too short an accumulation time may cause the sample spectrum to have a noncentral peak, or be nongaussian.

Enough scattering of the $10.6-\mu \mathrm{m}$ wavelength, 1-W coherent continuouswave output must be achieved to give a backscatter coefficient of $10^{-9} \mathrm{~m}^{-1}$ $\mathrm{Sr}^{-1}$. In the atmospheric aerosol conditions that prevailed, the lidar required about 50 ms to accumulate enough spectral realizations to accurately estimate the value of one representative wind speed value. This means that in a fullcircle rotational scan by the beam in $1.5 \mathrm{~s}$ corresponding to the MOD-OA turbine, 30 separate, equally spaced wind speed samples could have been taken, each representing a $12^{\circ}$ arc of the circle of rotation. The sample length was such that 10 samples per second were taken. This gave 15 samples around the circle and resolved variations out to a frequency of 7.5 times the rotation rate of a MOD-OA blade.

The accuracy of the wind measurement by lidar also depends upon placing the selected central value of the Doppler spectrum absolutely with respect to the 0 -speed or Doppler-shift value. The instrumental error in this process was found to be about $0.3 \mathrm{~m} / \mathrm{s}$. Because there was strong backscatter into the lidar receiver at small Doppler shift values from other parts of the beam, useful measurements in the range of 0 to $1.5 \mathrm{~m} / \mathrm{s}$ were not possible. Thus, low wind speed conditions may have resulted in distorted rotational time series of wind speed because the wind speed may have fluctuated in and out of the range in which the clean measurement is contaminated by backscatter noise. If a pulsed mode of operation could have been used, the receiver could have been switched to exclude the backscatter from undesired regions through which the light passed. Pulsed lidar would also provide additional control over the length and location of the active measurement volume of air.

In the rotational scanning mode, the laser beam traces out the surface of a right circular cone, as the center of the active lidar beam volume traces out a circle of a specified diameter. Thus the backscatter direction, which is the direction of the velocity component measured, is neither parallel to the axis of the cone, nor constant in direction. The ideal direction of the measurement would be parallel to the cone axis; so, an error exists in the 
measurement because of the off-axis directions of the beam. Figure 5.3 shows the geometry of the situation, where $V_{r}$ is the radial velocity actually measured, $v_{x}$ is the axial wind speed whose measurement is preferred, and $v_{y}$ and $V_{Z}$ are the velocity components normal to $V_{X}$ in the Cartesian coordinate system. The relation between $v_{r}$ and $v_{x}$ is, as we estimate it,

$$
v_{r}^{2}=v_{x}{ }^{2} \cos ^{2} \theta+\left(v_{y}{ }^{2}+v_{z} \cos ^{2} \theta\right) \sin ^{2} \theta .
$$

The cone half-angle is $10^{\circ}$, so when the rotation is such that $\theta=10$, Equation (5.1) reduces to

$$
v_{r}=\left[0.97 v_{x}^{2}+0.030\left(v_{z}^{2}\right)\right]^{1 / 2},
$$

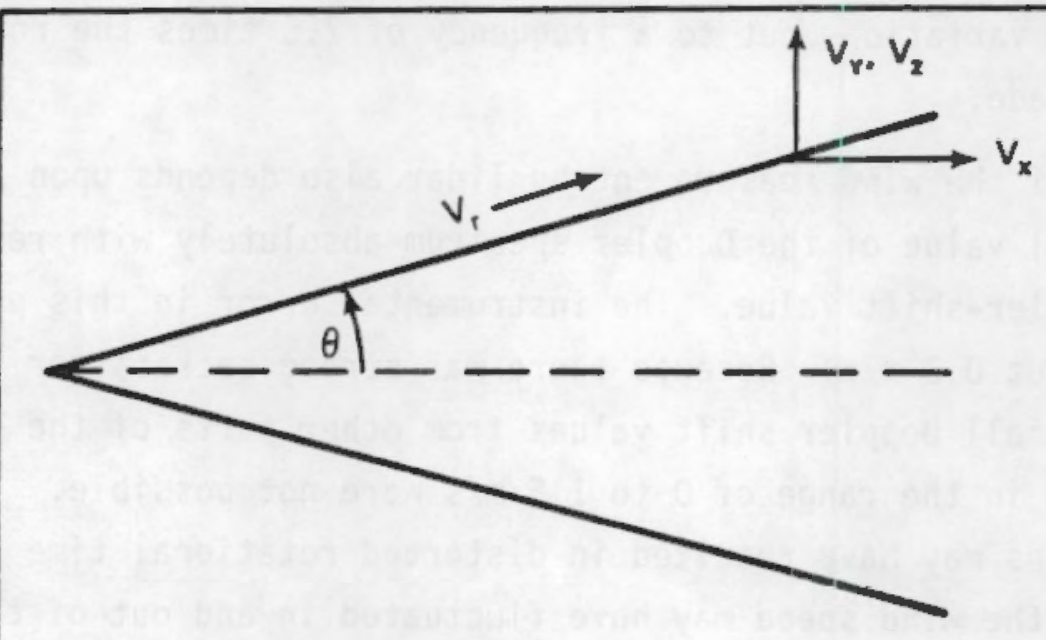

FIGURE 5.3. The Geometry of the Laser Beam Axis and the Relevant Wind Speed Components. $V_{r}$ is the radial velocity actually measured, $v_{x}$ is the axial wind speed whose measurement is preferred, and $V_{y}$ and $V_{z}$ are the velocity components normal to $V_{x}$ in the Cartesian coordinate system. 
and after some simplification to

$$
v_{r}=0.98 v_{x}\left\{1+0.015\left[v_{z}^{2} / v_{x}^{2}\right]\right\}^{1 / 2}
$$

Equation (5.3) indicates that no appreciable error is made in estimating $v_{x}$ using $v_{r}$ along cone elements for a $10^{\circ}$ cone used to scan circles with the active beam angle. [See also Hardesty, Korrell and Hall (1981, p. 5) for an analysis of the effect of a $10^{\circ}$ half-angle cone of scan that considers the rotating aspect of the sampling.]

Finally, some criterion is useful for rejecting velocity estimates from single Doppler-shift spectra when the signal part of the realization is so small that noise is significant. The method chosen by NOAA/WPL personnel for the present application was to define a simple measured signal-to-noise ratio, $\sigma / N$, as shown in Equation (5.4).

$$
\sigma / N=P_{k} /\left\{(1 / k) \sum^{k}|\phi-\bar{\phi}|\right\} \text {. }
$$

where $P_{k}$ is the maximum signal height in a Doppler spectrum and $\left\{1 / k \sum^{k} \mid \phi-\right.$ $\bar{\phi} \mid\}$ is the average of the absolute value of the deviation of the individual spectral estimates from the average value of all of the spectral estimates making a single usable spectrum. A schematic illustration of the spectral peak-to-noise ratio is shown in Figure 5.4. A minimum acceptable level was empirically selected by NOAA/WPL personnel based upon their experience. Although the lidar scanned across the incoming signals using a narrow band filter with a potential resolution of $30 \mathrm{KHz}$ or $0.16 \mathrm{~m} / \mathrm{s}$, accuracy of the matched filter method picking the speed of the equivalent Gaussian distribution of the individual Doppler spectral results gives an uncertainty of about $0.5 \mathrm{~m} / \mathrm{s}$. 


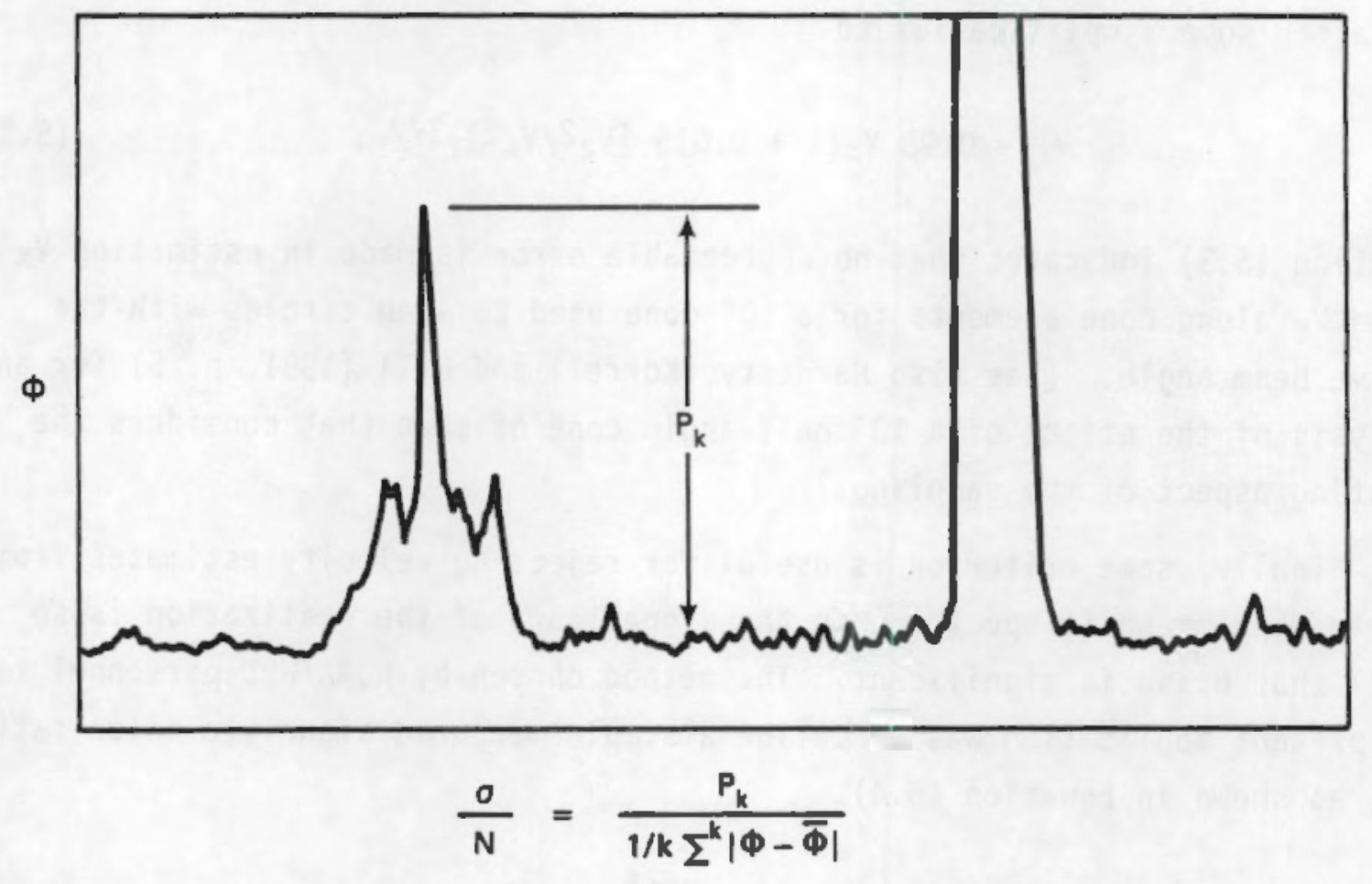

FIGURE 5.4. Hypothetical Plot of a Single Doppler Lidar Return Spectrum Showing Every Spectral Estimate, $\theta$, Versus Spectral Frequency, $n$. The height of the peak of the spectrum, representing the wind speed in the active volume, is labeled $\mathrm{Pk}$. 


\subsection{CONCLUDING REMARKS AND RECOMMENDATIONS}

\subsection{DEPENDENCE OF ROTATIONALLY SAMPLED WIND CHARACTERISTICS ON ROTOR SIZE}

The wind turbine problem to which the lidar experiment reported here was addressed is the variation that occurs in the high-frequency fluctuation of wind speed experienced by a rotor blade as a function of the blade radius, hub height, and rotation rate. The method used was to develop rotationally sampled time series of the actual wind speeds for each turbine configuration and as many wind conditions as possible. Two measurement and analysis tools were applied: the single-tower STRS-2 simulation, and the circle-scanning lidar Doppler measurement.

The rotationally sampled time series developed by each tool from a few useful cases of real winds were spectrally analyzed. The most clear display that addresses the functional relation between the rotationally sampled wind and the wind turbine configuration is shown in Figure 6.1. The total energy of fluctuation in the high-frequency part of the rotationally sampled wind spectrum above the frequency of half the rotation frequency of the blade is taken as a measure of the amount of wind fluctuation that affects the blade. This high-frequency variance is plotted against the nondimensional rotor radius, $R / H$, where $H$ is the hub height for both the STRS-2 method and the scanning lidar method. The data for three turbines are included: the MOD-OA, the MOD-2, and the MOD-5 400-ft diameter, 10-rpm rotor. The general trend of the relation is an increase in variance of the rotationally sampled wind speed at the blade as the nondimensional rotor radius increases. The STRS- 2 result appears more erratic than the lidar result, especially at the larger rotor radii. The same conclusion is drawn as reported by Connell and George (1983b): the rotationally sampled winds are more severe as observed for larger wind turbines, especially if they are built close to the ground.

The apparent way to decrease the severity of the turbulent wind effect on wind turbine rotors is to design with a decrease in the ratio of rotor radius to hub height, $R / H$. Because in most wind regimes increasing $H$ brings the rotor to an increased wind speed, the same power can be obtained with a smaller rotor radius, thus further decreasing the severity of rotationally 


\section{HIGH FREOUENCY VARIANCE OF ROTATIONAL' SPECTRA}

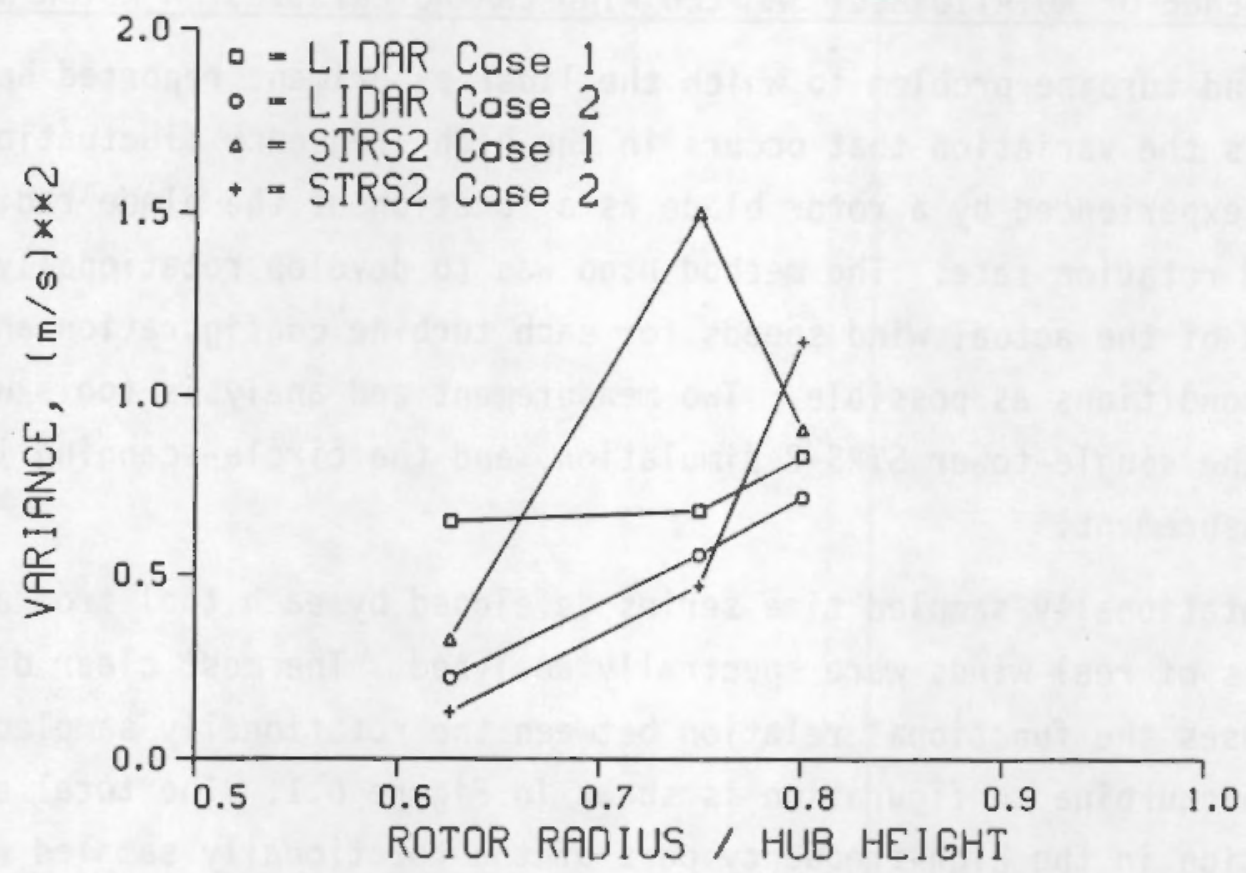

FIGURE 6.1. A Plot of the Total Energy of Fluctuation in the High-Frequency Part of the Rotationally Sampled Wind Spectrum Above the Frequency of Half the Rotation Frequency of the Blade. This highfrequency variance is plotted against the nondimensional rotor radius, $R / H$, where $H$ is the hub height. Relations derived from STRS-2 and lidar are shown for the MOD-OA, the MOD-2, and the MOD-5 configurations.

sampled wind. Two other factors not included in this analys is that would generally change with increasing height in a way to reduce the rotationally sampled wind severity are the magnitude and length scale of turbulence (Connell 1982). Another factor is that the rotation rate might be reduced in the more energetic wind, thus reducing the severity of effect rotating through the turbulence.

\subsection{RECOMMENDATION FOR CONTINUED RESEARCH}

The work reported herein is a very modest followup of some preliminary research that developed the basic ideas for STRS-2 and Doppler lidar methods for estimating, from measurements, the rotationally sampled wind. It appears 
that the rotationally scanning lidar has substantial potential to become an excellent mobile, nonintrusive tool for measuring the turbulent wind following the rotation of a turbine blade. A slight modification of the technique would even permit it to measure the wind as it tracks very near a selected part of a moving turbine blade.

A few upgrades of a lidar to allow faster, more noise-free measurement and accurate Doppler spectral analysis, as well as lower minimum detectable wind speeds, would provide reliable measurement of rotationally sampled wind information around a single circle of rotation. In addition to the signalprocessing hardware changes, it would help to add computer-controlled stepping motor drive of the laser beam orientation. This would allow a more reliable repeated scanning of a circle, as well as accurate scanning at a selected point near a blade of an actual wind turbine, synchronized with the rotation of the blade. Modification of the lidar to be accurate and sensitive enough in the pulsed, rather than the continuous wave, mode of operation would improve the spatial resolution of the measurements.

One of the current and upcoming interests for wind turbine aerodynamics is knowing the wind velocity continuously and simultaneously at several radial locations moving angularly with the rotating blade. The most successful method being developed for this purpose utilizes hotfilm anemometers mounted ahead of the leading edge of the blade (Sandborn and Connell 1984). The Doppler lidar method described in this report is not likely in the foreseeable future to provide measurements of wind at two or more radial locations simultaneously. Nor is the lidar discussed likely to be able to measure remotely the three components of the wind velocity without substantial development.

Although a lidar for continuing the testing of the simple one-radius circular scanning method would not be especially expensive, development of lidar for the purpose of three-dimensional velocity, multiradius simultaneous measurement would require substantial time, money, and talent. It could only be justified if the need for measurements of this type could be seen 5 years in advance. The additional advantages to consider are that it would require no towers, no fixtures attached to the turbine rotor, and could be installed at a remote location from a site of interest that had no place to install measurement equipment. The unit would have to use a combination of Doppler 
backscatter and either fringe-crossing or beam-crossing techniques to measure all three components of velocity at the same location.

\subsection{THE RELATIVE MERITS OF STRS-2 AND CIRCLE-SCANHING LIDAR}

The scanning lidar method is based upon measurement of a type that is less common in the experience of most of $u s$, and the STRS- 2 method is less direct because of its method of extrapolation but can use wind data from more ordinarily experienced anemometers. Therefore, a discussion of the relative merits of these techniques is important.

One advantage of STRS-2 is that it can be used with single vertical line of locations of wind data. The data can be artificial or it can be real data measured by any type of sensor. Another advantage of STRS-2 is that simultaneous time series for many radial locations can be simulated. Moreover, there may be a number of locations of interest at which measurements useful for STRS-2 analysis/simulation have already been taken, and in sone cases, no field program of measurements of wind velocity need be undertaken. In other places of interest, a tower already may be paid for and installed on the site and instrumented with a sufficient number of levels of conventional anemometers. The STRS-2 method has modest accuracy in representing the rotationally sampled wind at a specific site, out to 2 times the rotation rate of the turbine; at greater frequencies, the accuracy seems to diminish rather rapidly. However, 5TRS-2 is still vastly superior to other single-tower methods if crosswind input into rotational frequencies from the blade rotation frequency to about five times that frequency is of importance.

The Doppler lidar method is, in princlple and apparently in practice for stronger winds, significantly superior to the 5TR5-2 method if no multiradius concurrent circular paths of measurenent are required. The lidar actually measures along the crosswind circular path; the STRS-2 methed does not use actual measurements of wind around the crosswind circle.

If a substantial need can be foreseen for rotational measurements of wind velocity with lidar, it is recommended that the time and effort be expended to calibrate this tool against a known standard, such as a new, rather complete vertical plane array of anemometers on towers. It is further recommended 
that upgrades of such a lidar be made to improve its usefuiness. At that point, the amount of use expected would justify and require the dedication of a lidar to the purpose. 


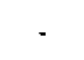

. 


\subsection{REFERENCES}

Connel1, J. R. 1980. Turbulence Spectrum Observed by a Fast-Rotating Wind Turbine Blade. PNL-3426, Pacific Northwest Laboratory, Richland, Washington, 35 pp.

Connell, J. R. 1982. "The Spectrun of Wind Speed Fluctuations Encountered by a Rotating Blade of a Wind Energy Conversion System." Solar Eneroy $29(5): 363-375$.

Connell, J. R., and R. L. George. 1983a. "A New Look at Turbulence Experi. enced by Rotating Wind Turbine." Proceedings of the Second ASME Wind Energy Symposium, pp. 455-480. American Society of Hechanical Engineers, Hew York, New York.

Connell, J. R., and R. L. George. 1983b. "Scaling Wind Characteristics for Designing Small and Large Wind Turbines." Proceedings of the American Solar Energy Society Annual Meeting (Hind Workshop VI), pp, 513-524. American Solar Energy Society. Hewark, DeTaware.

Connell, J.R., and R. L. George. 1987. "Accurate Correlation of Wind Turbine Response with Wind Speed Using a New Characterization of Turbulent Wind." Journal of Solar Energy Engineering 109:321-329.

Conne11, J. R., V. R. Morris and M. E* Hinchee. 1987. "Input Turbulence Features at agawat-size Wind Turbine Medicine Bow, Wyoming." Paper presented at the 6th ASME Wind Energy Symposium, Dallas, Texas, February 15-18, 1987 .

Comell, J. R., V. R. Morris, D. C. Powell and G. L. Gower. 1988. The PNL Single-Tower Measurement Model of Rotationally Sampled Turbulent Wind, with User's Guide for STRS2PC. PNL-6580, Pacific Northwest Laboratory. Richland, Washington.

Hardesty, R. M., J. A. Korrell and F. F. Hall. 1981. Lidar Measurement of Wind Velocity Turbulence Encountered by a Rotating Wind Turbine. DOE/RL/10236-81-1, U.S. Department of Energy, Avallable at NTIS, Springfield, Virginia, $23 \mathrm{pp}$.

Hardesty, R. M., R. J. Keeler, M. J. Post and R. A. Richter. 1981. "Characteristics of Coherent Lidar Returns fron Calibration Targets and Aerosols." Journal of Applied Optics 20:3763-3769.

Hardesty, R. M. and B. F. Heber. 1984. "Lidar Neasurement of Turbulence Encountered by Horizontal Axis Wind Turbines." Journal of Atmospheric and Oceanic Technology 4(1):191-203.

Sandborn, V. A*, and J. R. Conne11. 1984. Heasurement of Turbulent Wind Velocities Using a Rotating Boom Apdaratus. PNL-4888, Pacific Northwest Laboratory, Richland, Washington. 
. 


\section{DISTRIBUTION}

No. of

Copies

OFFSTIE

10 DoE/office of Scientific and Technical Information

C. 1. Aspliden

Battelle, Pacific Northwest Laboratories 370 L'Enfant Promenade, \$W Washington, DC 20024-2115

J. Cadogan

U.S. Department of Energy Wind/Ocean Technologies bivision 1000 Independence Avenue Forrestal Bullding, Room 5F064 washington, DC 20585

G. P. Tennyson

U.S. Department of Energy

Albuquerque Operations office P.0. Box 5400

Albuquerque, NM 8710

S. H. Chan

Systens Control, Inc. 1801 Page Mill Road

P.0. Box 10025

Palo Alto, CA 94303

R. H. Kirchhoff

University of Massachusetts

Department of Mechanical

Engineering

Amherst, MA 01003

P. Klimas

Sandia National Laboratories

Division 6225

A)buquerque, NM 87185
No. of

Copies

P. M. Moretti

Ok 7 ahoma State University

Mechanical and Aerospace

Engineering

Engineering North 218

stillwater, of 74074

D. C. Reda

Sandia National Laboratories

Division 6225

Albuquerque, NH 87185

R. B. schlueter

Michigan State University

Department of Electrical Engineering

East Lansing, MI 48824

D. Spera

HASA/Lewis Research Center

21000 Brookpark Road

Cleveland, of 44135

J. P. Sullivan

Purdue University

Aeronautics Astronautics

Grisson Hall

W. Lafayette, IN 4790 ?

R. M. Sundar

Enbry Riddle Aeronatical University

$3200 \mathrm{~K}$. Willow Creek Road

Prescott, AZ 86301

R. W. Thresher

Solar Energy Research Inst tute 1617 Cole Boulevard

Golden, Co 80401

V. A. Vachon

P. 0. Box 149

Manchester, MA 01944 
No. of

Copies

P. Veers

2700 Del Medio Court 1304

Mountain View, CA 94040

S. N. Nalker

Oregon State University

Department of Mechanical Engineering

Corvallts, oR 97331

\section{ONSITE}

DoE Richland Operations office

J. J. Sutey/D. R. Segna
No. of

Copies

35 Pacific Northwest Laboratory

J. C. Barnard

J. R. Connel1 (10)

C. E. Elderkin

U. L. Elliott

J. W. Falco

M. J. Graham

J. M. Hales

P. C. Hays

R. A. Keefe (7)

V. R. Morris

E. L. Owczarski

J. A. Stottlemyre

L. L. Wendell

R. F. Nildung

Publishing Coordination

Technical Report Files (5) 